\title{
Modelling the Triaxial Compression Behavior of Loess Using the Disturbed State Concept
}

\author{
Yali Xu $\mathbb{D}^{1},{ }^{1}$ Panpan Guo $\mathbb{D}^{2},{ }^{2}$ Yixian Wang $\left(\mathbb{D},{ }^{3}\right.$ Cheng-Wei Zhu, ${ }^{4}$ Kang Cheng, ${ }^{2,5}$ \\ and Gang Lei ${ }^{2,6}$ \\ ${ }^{1}$ School of Urban Construction and Transportation, Hefei University, Hefei 230601, China \\ ${ }^{2}$ Research Center of Coastal and Urban Geotechnical Engineering, Zhejiang University, Hangzhou 310058, China \\ ${ }^{3}$ School of Civil Engineering, Hefei University of Technology, Hefei 230009, China \\ ${ }^{4}$ Institut für Geotechnik, Universität für Bodenkultur, Feistmantelstrasse 4, A-1180 Vienna, Austria \\ ${ }^{5}$ China Railway $11^{\text {th }}$ Bureau Group Co., Ltd., Wuhan 430061, China \\ ${ }^{6}$ Beijing Urban Construction Design \& Development Group Company Limited, Beijing 100037, China
}

Correspondence should be addressed to Panpan Guo; pp_guo@zju.edu.cn and Yixian Wang; wangyixian2012@hfut.edu.cn

Received 24 December 2020; Revised 26 January 2021; Accepted 9 February 2021; Published 23 February 2021

Academic Editor: Ma Jianjun

Copyright (C) 2021 Yali Xu et al. This is an open access article distributed under the Creative Commons Attribution License, which permits unrestricted use, distribution, and reproduction in any medium, provided the original work is properly cited.

\begin{abstract}
This paper investigates the triaxial compression behaviour of Q3 loess soil and the construction of a constitutive model accounting for the structural effect of loess on the basis of the disturbed state concept. By analyzing the triaxial compression testing results, we have established a new disturbing function with respect to the volumetric and shear moduli parameters. A research into the evolution laws of the disturbing function was also conducted, followed by the construction of a constitutive model for loess soil as well as the verification of the constitutive model with model test results. The results indicate that the double-parameter disturbing function evolves in an exponential form, capturing well the effect of moisture content and confining pressure on the loess structural behavior. The parameters of the constructed constitutive model based on the disturbed state are easy to be obtained and have clarified physical meanings. Considering the effectiveness in capturing the structural behavior of the loess, the constructed constitutive model has a great potential to be applied in the engineering practice in the loess area. The constructed constitutive model based on the disturbed state concept provides new ideas for the study of the structural constitutive model of loess, which is theoretically significant.
\end{abstract}

\section{Introduction}

A constitutive model describing the stress-strain relations of geomaterials is the key to the accurate calculation in engineering practice $[1,2]$. It has been baffling geotechnical engineers for a long time. Due to the fact that the existing constitutive model based on the remolding soil and the saturated soil cannot truly describe the mechanical properties of the structural natural soil, the structure of the soil has become the focus and the difficulty of the research of the constitutive model. The structure of the soil refers to the comprehensive effect of the 'spatial arrangement' and the 'coupling' between soil particles. Due to the differences in the components, the forming process, and the forming experience, the structures of the natural soil are diverse. It is the key for the field of the geotechnical engineering to accurately describe the mechanical properties of the structural soil and to construct the proper constitutive model.

The year of 1925 witnessed that it was the first time that Terzaghi noticed the structure of clay and proposed the 'honeycomb structure,' and later Goldschmidt puts forward the structure of the rack arrangement of the soil or the structure of the book, both of which were the beginning of the study of the issue of the structure. Subsequently, many researchers all over the world have conducted many research studies on the structural soil. Wong [3] established a constitutive model for hardened structures by studying the mechanical properties of clay before and after yielding. Liu 
and Carter [4] proposed a Cam-Clay model for the structural clay. Desai [5-9] proposed an elasto-plasticity model for clay based on the disturbed state theory. Based on the damage mechanics theory, Shen [10-12] proposed a complex model, a binary-medium model, and a pile-masonry model for the structured soil. Xiao et al. [13-16] conducted a series of studies on the structure of the overconsolidated soil. Chen [17] studied the microstructure of the unsaturated structural soil with the CT method and constructed an elasto-plasticity model for structural soil. Fang et al. $[18,19]$ established the relationship between the microscopic test data and the macroscopic phenomena of the soil through the CT-triaxial test, so as to obtain the structural evolution laws of the structural soil. Jiang et al. [20, 21] applied the particle-flow software to simulate the combination and the arrangement of the structural soil and studied the behavior of structural soil.

The mechanical properties of the natural soil are of different features, due to the differences in the geological ages, the forming conditions, and the process of the soil formation. In particular, the loess, one of the typical special soil, has the mechanical properties different from the ordinary clay and the sandy soil. Therefore, it is necessary to carry out the study of the loess. Miao et al. [22] developed a constitutive model for the abrupt instability of the loess. Gao et al. [23] and Romero and Simms [24] conducted SEM tests to study the microstructure of the loess before and after the occurrence of collapse. Lei and Tang [25] and $\mathrm{Li}$ et al. [26] carried out CT tests to investigate the microstructural evolution of the loess by using the triaxial and uniaxial compression tests. Luo et al. [27] quantitatively analyzed the structural loess from the perspective of the soil mechanics. On the basis of the compression tests, they proposed a parameter called the comprehensive structure potential, which can quantitatively describe the soil structure. By using the comprehensive structure potential, Chen et al. $[28,29]$ studied the collapsibility of the loess through a series of tests at different moisture contents. Wang et al. [30] studied the collapsibility characteristics of the loess through the dry-wet cycle.

However, the study of the microstructure is not only limited by the instruments but also affected by the dispersion of the samples. For the study which is carried out from the perspective of the soil mechanics, it is impossible to overcome the obstacles of the structural property strength caused by the arrangement and the cementation. Therefore, Xu $[31,32]$ described the mechanics of the structural properties of the loess under one-dimensional compression state for the first time and constructed the disturbance constitutive model for one-dimensional compression state condition. It can be seen that the disturbance state theory can not only avoid the problem of measuring the change of the microstructure directly and quantitatively but also explain the response of the macromechanics through the change of the microstructure.

Loess is the quaternary sediment formed in the arid and semiarid climate. The mineral composition of the loess in different regions varies widely, and the amount and the proportion of the mineral composition as well as the diversified content of the weathering-resistant mineral composition are different, both of which contribute to the fact that the mechanical properties vary greatly. The main body of the loess is composed of the coarse powder which is highly active in being immersed in water, and the granules composed of fine powder and clay in the loess cause loess having a different collapsibility. The content of clay in the loess is relatively small, and its hydrophilicity is different. The fact that the composition and the proportion of the clay mineral are different, to some extent, leads to the different collapsibility of the loess. Kaolinite and hydromica can promote the occurrence and development of the collapsing of the loess, while montmorillonite and nontronite have special expansibility and can prevent the development of the collapsing of the loess. The powder particles in the loess are the main part of the constitution of the granules. The powder particles deposit with the soluble salts, and a combination of them forms a cementitious connection in the lava, both of which contribute to the special structural properties of the loess. Studying the structure of the loess and accurately describing its mechanical behavior is of great significance to the research of the constitutive model in the field of geotechnical engineering, especially to the engineering practice in the northwest of China.

This paper investigates the triaxial compression behavior of the structural loess collected from the southern suburb of $\mathrm{Xi}$ 'an, on the basis of the disturbed state concept and considering the composition and the characteristics of the soil. Conventional triaxial compression tests under consolidated and drained condition were performed on remolding and natural loess soil specimens of various water contents. A disturbing function with its parameters being the volumetric and shear moduli was established. The evolution laws of the double-parameter disturbing function were discussed for different moisture contents and confining pressures. On the basis of this discussion, a disturbance constitutive model reflecting the structure of the loess was constructed. By comparing the finite element analysis results using the proposed constitutive model with the rafted pile group model test results, the effectiveness of the proposed constitutive model was verified.

\section{Materials and Methods}

2.1. Structural Loess. The natural specimens of loess, which were collected in a building site near to the Xi'an southern suburb, were adopted in this study. The cover depth of the collected loess in the building site was about $5.0 \mathrm{~m}$. The color of the plastic loess was yellow. According to the Chinese Soil Classification System, this type of soil can be classified as the typical Q3 loess. Standard proctor tests were performed to measure the optimum moisture content as well as the maximum dry density. The material parameters are summarized in Table 1.

\subsection{Sample Preparation}

2.2.1. Natural Samples. The loess was excavated using hands for the purpose of avoiding disturbance and then was trimmed to standard specimens in steel split molds. The samples were cut into cylindrical shape with the height being 
TABLE 1: Material parameters of the natural loess investigated in this study.

\begin{tabular}{|c|c|c|c|c|c|c|c|c|c|c|c|c|}
\hline Parameter & $G_{s}$ & $\rho_{\text {nd }}$ & $e$ & $w_{p}$ & $w_{l}$ & $\rho_{d d}$ & $w_{s m c}$ & $w_{\text {omc }}$ & $\rho_{m d d}$ & $f_{c c}$ & $w_{n m c}$ & $w_{p i}$ \\
\hline Magnitude & 2.71 & 1.476 & 1.258 & 18.9 & 31.3 & 1.2 & 46.5 & 28 & 1.67 & 0.019 & 23 & 12.4 \\
\hline
\end{tabular}

Note. $G_{s}=$ specific gravity; $e=$ void ratio; $w_{l}=$ liquid limit $(\%) ; w_{s m c}=$ saturated moisture content $(\%) ; \rho_{m d d}=$ maximum dry density $\left(\mathrm{g} / \mathrm{cm}^{3}\right) ; w_{n m c}=$ natural moisture content (\%); $\rho_{n d}=$ natural density $\left(\mathrm{g} / \mathrm{cm}^{3}\right) ; w_{p}=$ plastic limit $(\%) ; \rho_{d d}=\operatorname{dry} \operatorname{density}\left(\mathrm{g} / \mathrm{cm}^{3}\right) ; w_{\text {omc }}=$ optimum moisture content $(\%) ; f_{c c}=$ coefficient of collapsibility; and $w_{p i}=$ index of plasticity.

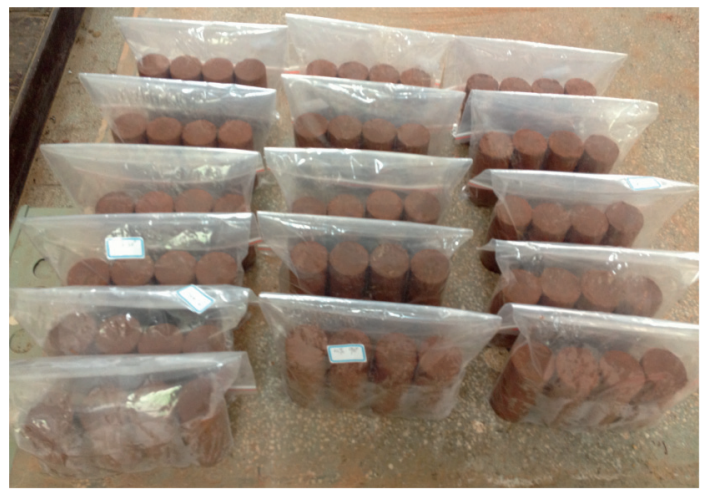

Figure 1: Photograph of natural structural loess samples.

$80 \mathrm{~mm}$ and the diameter being $39.1 \mathrm{~mm}$, as shown in Figure 1 . The discrepancy in the soil density was controlled to be no more than $0.03 \mathrm{~g} / \mathrm{cm}^{3}$, and the discrepancy in the soil moisture content was controlled to be no more than $1 \%$.

2.2.2. Remolding Samples. In the preparation of the remolding soil samples, what is first and foremost is that the natural soil was made into pulverized and then sieved with a sifter of $1 \mathrm{~mm}$ in sieve diameter. Then, after the soil was stirred evenly, we measured the moisture content and packed them into sealed bags. By using the natural dry density, the mass of different samples was calculated. Then, according to the samples needed for different tests, the samples were obtained with the method of stratified sample pressing. Following the standard procedure, the remolding loess specimens were compacted to the required dry density in five layers.

2.2.3. Sample Saturation. With the help of the vacuum pumping method, the loess specimens were saturated. Using the distilled water, all the specimens were utterly saturated for 1 day under the condition of vacuum. The considered magnitudes of the loess moisture contents were controlled adopting the natural air drying and moisture migration methods.

2.2.4. Sample Moisture Content. In order to keep the different structural properties, the water contents of the compacted loess specimens were adjusted to the set water contents (i.e., $16 \%, 8 \%, 28 \%, 46.5 \%$, and $22 \%$ ) by dehumidification or humidification. For the specimens with a water content less than $22 \%$, the water content was improved to be $22 \%$ by adopting the syringe dripping method. For the samples with a water content greater than $8 \%$, the specimens were air-dried to decrease the water content to be $8 \%$. Once the set water contents were achieved, the specimens were wrapped with the preservative film and were put inside a moisturizing cabinet. The specimens were stored inside the moisturizing cabinet for more than 2 days so that a homogenous water distribution was achieved. The weight of the water for humidification or dehumidification was calculated by

$$
m_{w}=\frac{\left(w_{1}-w_{0}\right) m_{0}}{1+w_{0}}
$$

where $m=$ weight of water to be added $/$ removed, $m_{0}=$ initial sample weight, $w_{0}=$ sample water content, and $w_{1}=$ target water content.

2.3. Triaxial Compression Test Method. Conventional triaxial compressive tests [33-35] were performed adopting a straincontrolled triaxial compression apparatus. A schematic of the strain-controlled triaxial compression testing apparatus is presented in Figure 2. As shown in Figure 2, this apparatus mainly consists of the pressure chamber, axial loading system, confining pressure system, and pore pressure measurement system. This apparatus was designed based on the MC shear strength concept to determine the stress versus strain relations and the ultimate shear strength of the specimens under various confining pressures [36]. The confining pressure is applied on the specimens within the device chamber using the loading system, and the vertical stress is applied on the specimens using the system of axial loading. The system of axial loading can control the strain rate and keep a constant confining pressure. With increasing the deviator stress, the specimens reach the limit equilibrium state, and the shear failure occurs finally. The specimens are tested under consolidated and drained conditions with a shear rate of $0.5 \mathrm{~mm} / \mathrm{min}$ and confining pressures of $50,100,200$, and $300 \mathrm{kPa}$. The shear failure point is reached 


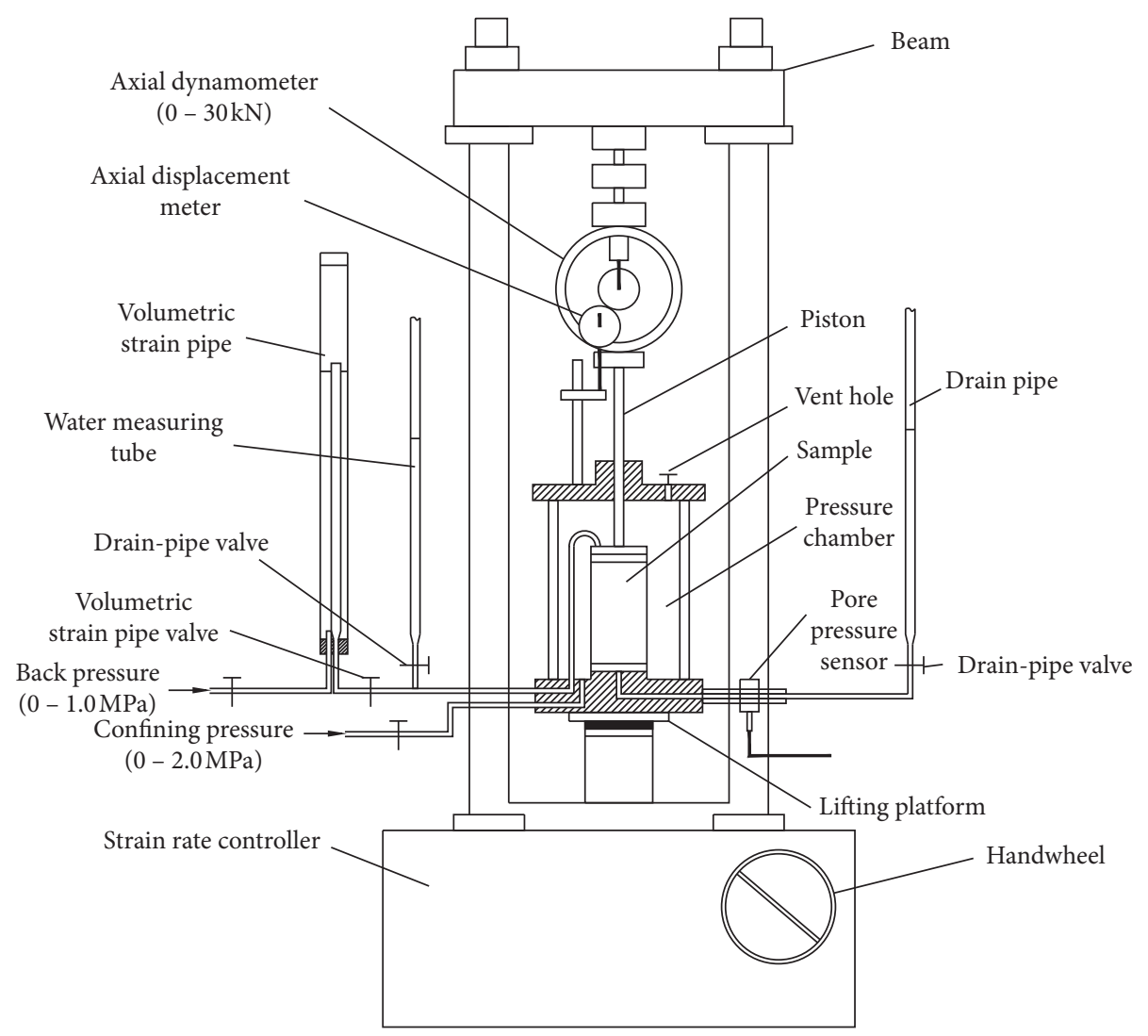

FIgURE 2: Schematic diagram of the strain-controlled triaxial compression testing apparatus.

corresponding to the peak deviator stress on the stress versus strain curve. When there is no peak value, the deviator stress corresponding to an axial strain of $15 \%$ is regarded as the shear failure point [37]. The experiments proceed until reaching a $19 \%$ axial strain.

\section{Results}

3.1. Stress-Strain Relations. The relations between deviatoric stress (i.e., $\sigma_{1}-\sigma_{3}$ ) and axial strain (i.e., $\varepsilon_{1}$ ) for natural loess specimens under triaxial compression at various water contents and different confining pressures are presented in Figure 3. It can be indicated in Figure 3 that the effect of confining pressure on the stress versus strain relations of the natural loess is remarkable. When the confining pressure becomes larger, the shear strength of the natural soil under each respective water content increases, but the magnitudes of the increases are different. When the confining pressure and the water content are both relatively low $(w=8 \%$ and $\sigma_{3}=50,100 \mathrm{kPa}$ ), the structural properties of the natural soil are strong and are relatively remarkable in the elastic stage. The confining pressure does not damage the initial structure of the natural soil, so the shear strength changes greatly when the comparison of the shear strength before and after structural failure is made. Therefore, the curves of the stressstrain relationship exhibit a typical softening type. With an increase in the confining pressure, the structure is gradually damaged. Accordingly, the curves of the stress-strain relationship gradually change from the softening type to the hardening type, and it is especially conspicuous when the confining pressure reaches $100 \mathrm{kPa}$. At a confining pressure, the curves of the stress-strain relationship of the natural soil specimens under relatively high water contents $(w=16 \%$, $22 \%, 28 \%$, and $46.5 \%$ ) basically show a hardening type. In addition, at a relative low confining pressure (e.g., $50 \mathrm{kPa}$ ), the stress-strain relations for natural loess specimens are of softening type under relative low water content. The softening type stress-strain relations transform into hardening type when the water content is from low to high. This is because that an increase in the water content has destroyed the original cementation.

The relations between deviator stress and axial strain for the remolding loess specimens under various confining pressures and water contents are shown in Figure 4. It can be indicated from Figure 4 that the confining pressure exerts an effect on the stress-strain relations of the remolding soil, but the effect is relatively slighter. When the confining pressure becomes larger, the shear strength of the remolding soil increases, but the magnitude of the increase becomes smaller. The sieving process in the preparation of remolding loess specimens has destroyed the original cementation in the natural loess soil. The weak cementation generated during sample preparation is reflected only at a relatively low water content and confining pressure. In detail, the stress- 

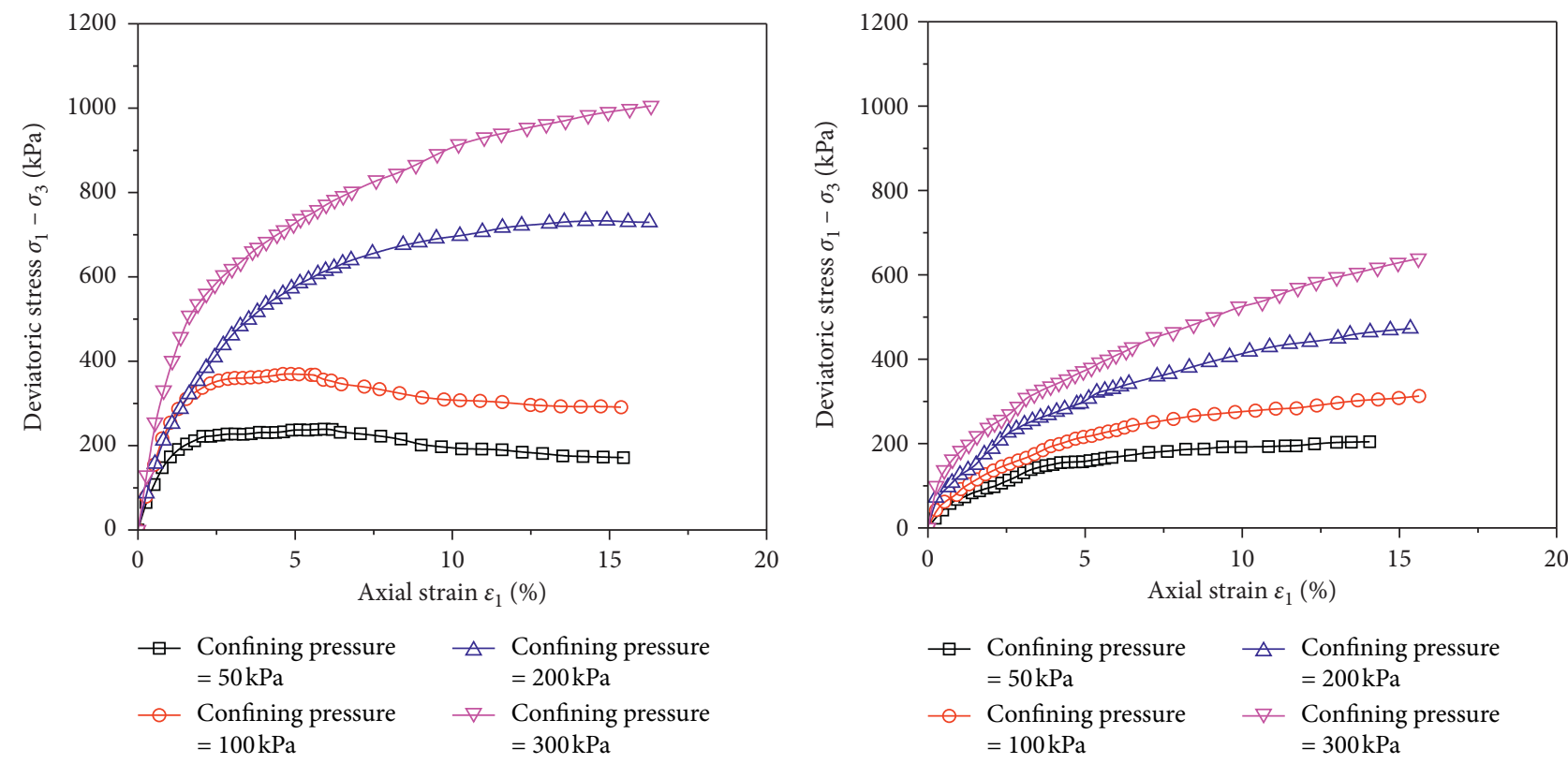

(a)

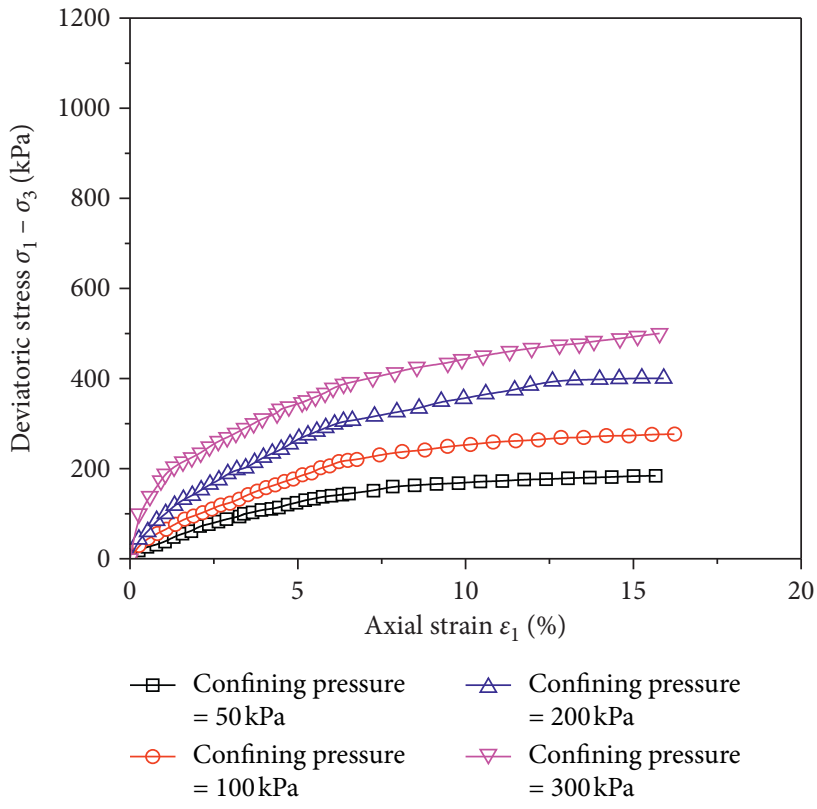

(c)

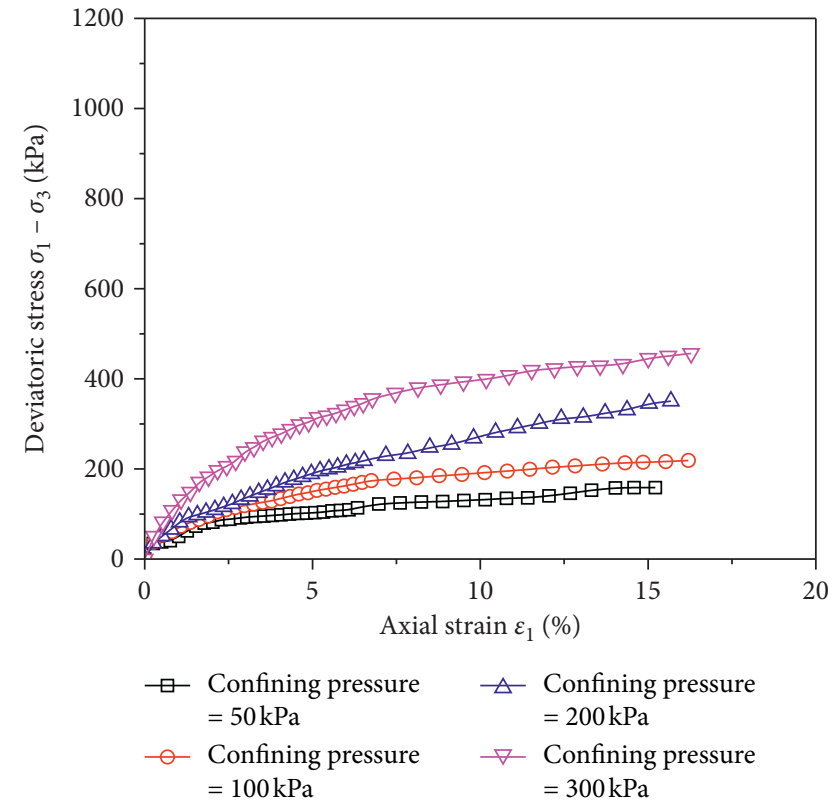

(d)

Figure 3: Continued. 


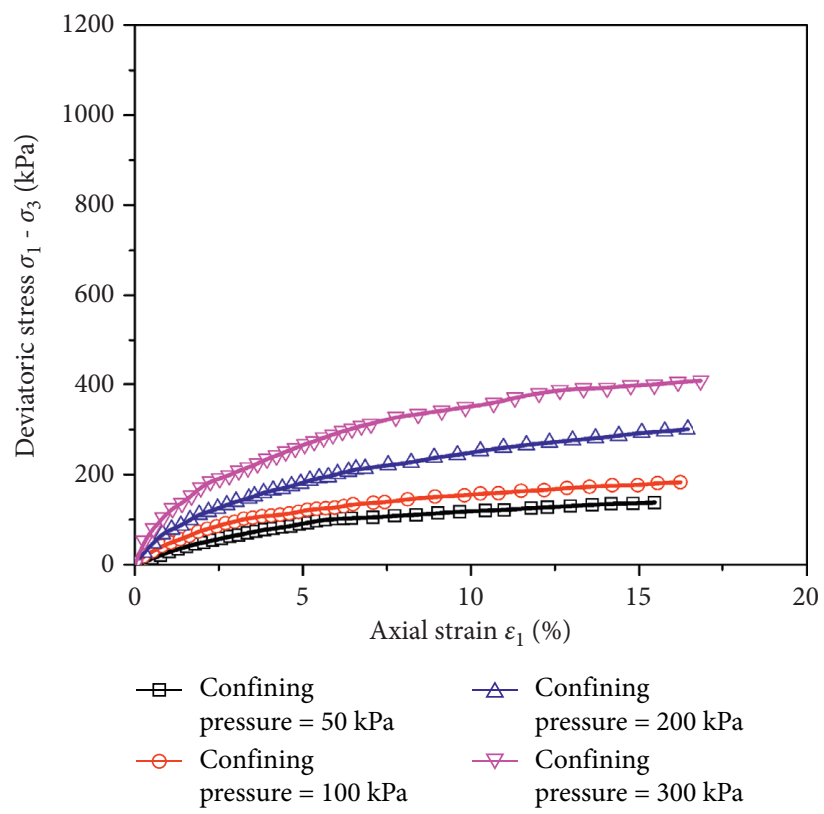

(e)

FiguRE 3: Deviatoric stress-axial strain relations for natural loess specimens prepared at different water contents. (a) $8 \%$; (b) $16 \%$; (c) $22 \%$; (d) $28 \%$; (e) $46.5 \%$.

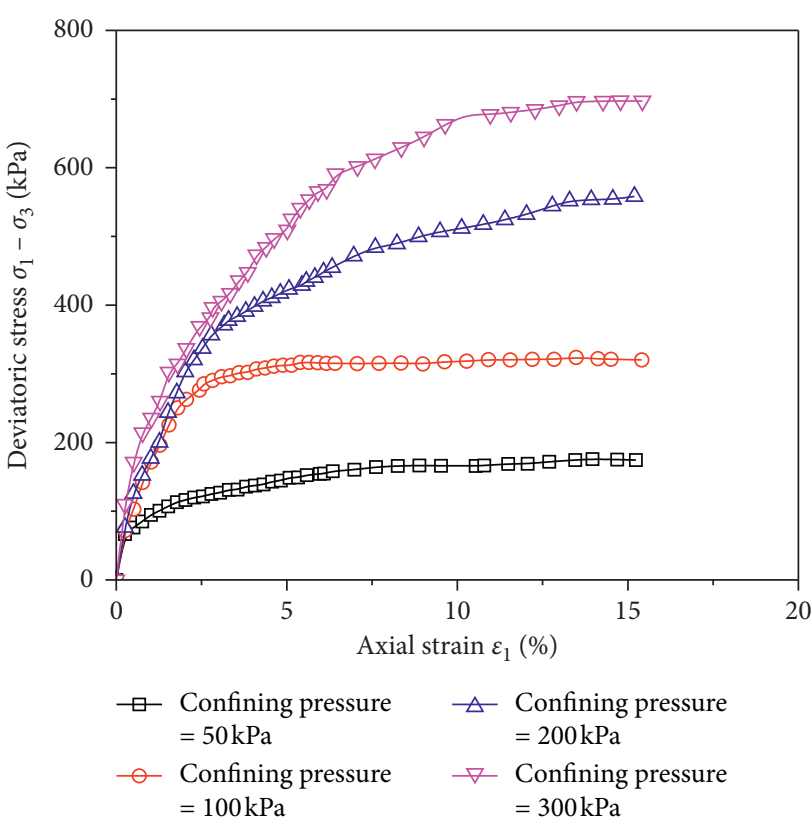

(a)

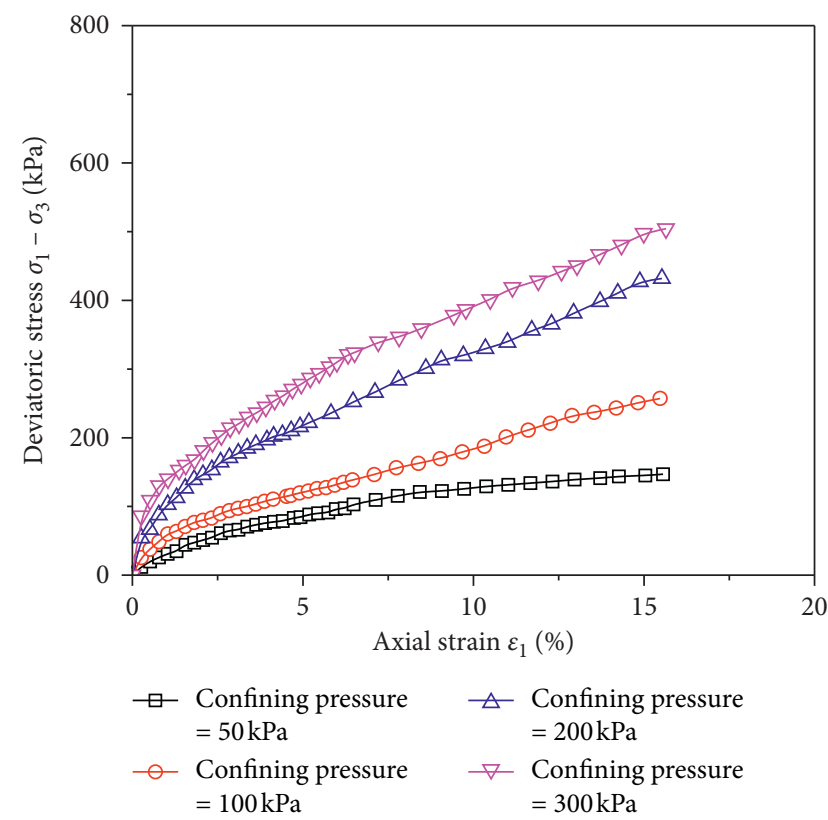

(b)

Figure 4: Continued. 


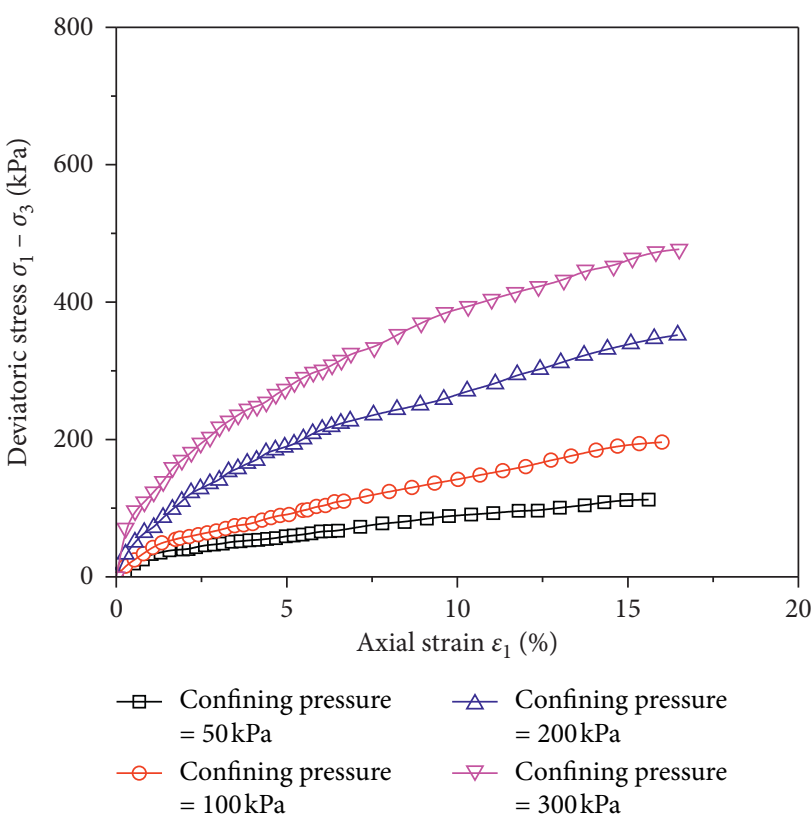

(c)

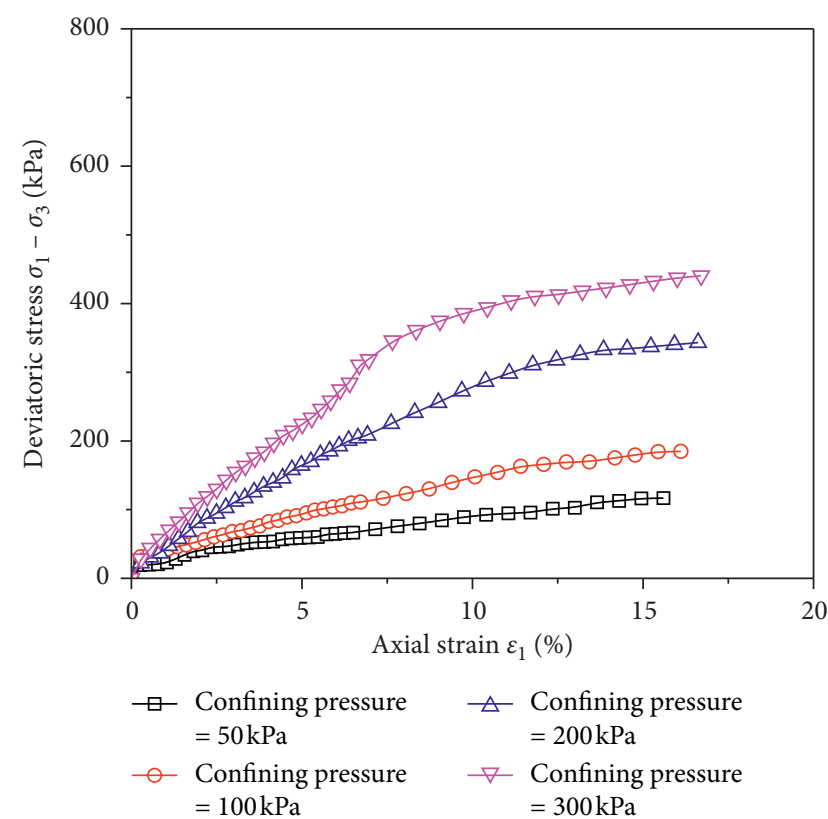

(d)

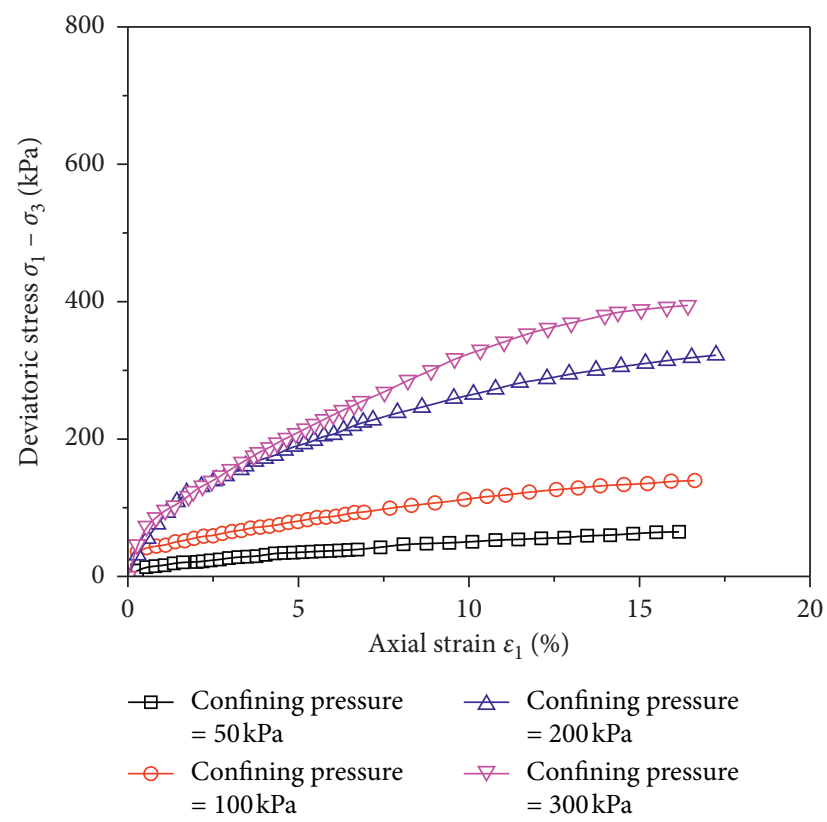

(e)

FiguRE 4: Deviatoric stress-axial strain relations for remolding loess specimens with various water contents. (a) $8 \%$; (b) $16 \%$; (c) $22 \%$; (d) $28 \%$; (e) $46.5 \%$.

strain relations for remolding loess specimens are of hardening type at a water content other than $8 \%$. And, the stress changes slightly as the change of confining pressure. The attenuation of the stress is prominent only at a relatively high water content (i.e., $w=46.5 \%$ ).

As a whole, because of the cementation and arrangement effects caused by climate and characteristic ingredient, the strength of natural loess is higher at a relatively low water content and a relatively high confining pressure. By increasing the water content, the structural strength of natural loess shows an intense attenuation at a relatively large confining pressure. The stress versus strain relations for remolding loess are generally hardening type and are not affected significantly by confining pressure and water content.

\subsection{Disturbing Functions}

3.2.1. Definition. The disturbed state theory was established by Desai in 1974. According to the disturbed state concept, 
when any material is subjected to an external load, the change of the internal microstructure of the material will inevitably cause the reflection of the external macroscopic mechanics of the material. For the internal of the material, the microstructure will change from the (original) relatively intact state to the fully adjusted state. The disturbance procedure can be depicted using a disturbing function or disturbance factor, and the disturbance evolution is described by the macroscopic measurement so that the constitutive relationship of the material is simulated. The disturbing function is a function that reflects the macroscopic behavior and the internal mechanism of the microscopic changes. Whether its evolution law is reasonable or not will directly determine whether the constitutive model can truly reflect the mechanical response of the soil or not. Therefore, the core issue of constructing a constitutive model for structural loess soil at the disturbed state is to reasonably establish the disturbing function and to study its evolution laws.

In order to consider the contribution of deviatoric stress and spheric stress to its strain, we establish the relation between the modulus of the spheric stress (i.e., volumetric modulus) and the disturbing function and the relationship between the modulus of the deviator stress (i.e., shear modulus) and the disturbing function. Therefore, the disturbing function based on the volumetric modulus and the shear modulus is defined as follows:

$$
\begin{aligned}
& D_{v}=\frac{\left(K_{i}-K\right)}{\left(K_{i}-K_{c}\right)}, \\
& D_{s}=\frac{\left(G_{i}-G\right)}{\left(G_{i}-G_{c}\right)},
\end{aligned}
$$

where $K_{i}=$ volumetric modulus at the relatively intact state ( $K_{i}$ can be calculated through $K_{i}=E_{i} /\left(3\left(1-2 \mu_{i}\right)\right)$ where $E_{i}$ and $\mu_{i}$ are, respectively, elastic modulus and Poisson's ratio of undisturbed loess soil), $K_{c}=$ volumetric modulus at the fully adjusted state $\left(K_{c}\right.$ can be calculated through $K_{c}=E_{c} /\left(3\left(1-2 \mu_{c}\right)\right)$ where $E_{c}$ and $\mu_{c}$ are, respectively, elastic modulus and Poisson's ratio of remolding loess soil), $G_{i}=$ shear modulus at the relatively intact state $\left(G_{i}\right.$ can be calculated through $G_{i}=E_{i} /\left(2\left(1+\mu_{i}\right)\right)$ where $E_{i}$ and $\mu_{i}$ are, respectively, elastic modulus and Poisson's ratio of undisturbed loess soil), and $G_{c}=$ shear modulus at the fully adjusted state $\left(G_{c}\right.$ can be calculated through $G_{c}=E_{c} /\left(2\left(1+\mu_{c}\right)\right)$ where $E_{c}$ and $\mu_{c}$ are, respectively, elastic modulus and Poisson's ratio of remolding loess soil).

3.2.2. Evolution Laws. The evolution characteristics of the disturbing functions based on volumetric modulus and shear modulus are shown in Figures 5 and 6, respectively. It can be revealed from Figure 5 that both the confining pressure and the water content have an effect on the volumetric modulus of the loess. The effect is reflected in the disturbing function. It has been indicated that the water content has a relatively great effect on the evolution laws of the disturbing function for the natural soil, while the water content has a slighter effect on the evolution laws of the disturbing function for the remolding soil. In the cases of low confining pressures, the evolution laws of the disturbing function for the natural soil change more slightly than that for the remolding soil, while in the cases of high confining pressures, the evolution laws of the disturbing function for the natural soil change more greatly than that for the remolding soil. In the cases of the same water content, the confining pressure has a greater effect on the evolution laws of the disturbing function for the natural soil, but has a slighter effect on the evolution laws of the disturbing function for the remolding soil.

It can be vividly revealed from Figures 5 and 6 that the evolution laws of the disturbing functions based on volumetric modulus and shear modulus for natural and remolding loess soil specimens can be well fitted by two exponential functions.

As shown in Figure 5, the disturbing function based on volumetric modulus can be fitted by

$$
1-D_{v}=A_{v} e^{-Z_{v} \varepsilon_{v}} .
$$

As shown in Figure 6, the disturbing function based on shear modulus can be fitted by

$$
1-D_{s}=A_{s} e^{-Z_{s} \varepsilon_{s}},
$$

where $D_{v}$, and $D_{s}$ are, respectively, the disturbing functions based on volumetric modulus and shear modulus and $A_{v}$, $Z_{v}, A_{s}$, and $Z_{s}$ are the parameters of the disturbing functions.

The values of the disturbing function parameters, namely, $A_{v}, Z_{v}, A_{s}$, and $Z_{s}$, in the disturbing functions for the natural and remolding loess specimens (see equations (4) and (5)) can be obtained through nonlinear curve fit with the least square method. Figures 7 and 8 summarize the magnitudes of the parameters of the disturbing functions for natural and remolding loess specimens prepared at various confining pressures and water contents. On the basis of the laboratory tests, the values of the parameters of the disturbing function for soil specimens under various confining pressures and water contents can be obtained. It can be indicated from Figures 7 and 8 that the disturbing function parameters vary, depending on the magnitudes of confining pressure and water content. However, a stable rhythm cannot be observed in the effect of confining pressure and water content on the disturbing function parameters. Therefore, more experimental research is required for the identification of this influencing mechanism. These disturbing function parameters and the evolution laws of the disturbing functions lay the foundations for establishing the constitutive model for structural loess soil based on the disturbed state concept.

\section{Modelling and Discussion}

4.1. Model Formulation at the RI State. Based on the disturbed state concept, the relatively intact (RI) state can be 

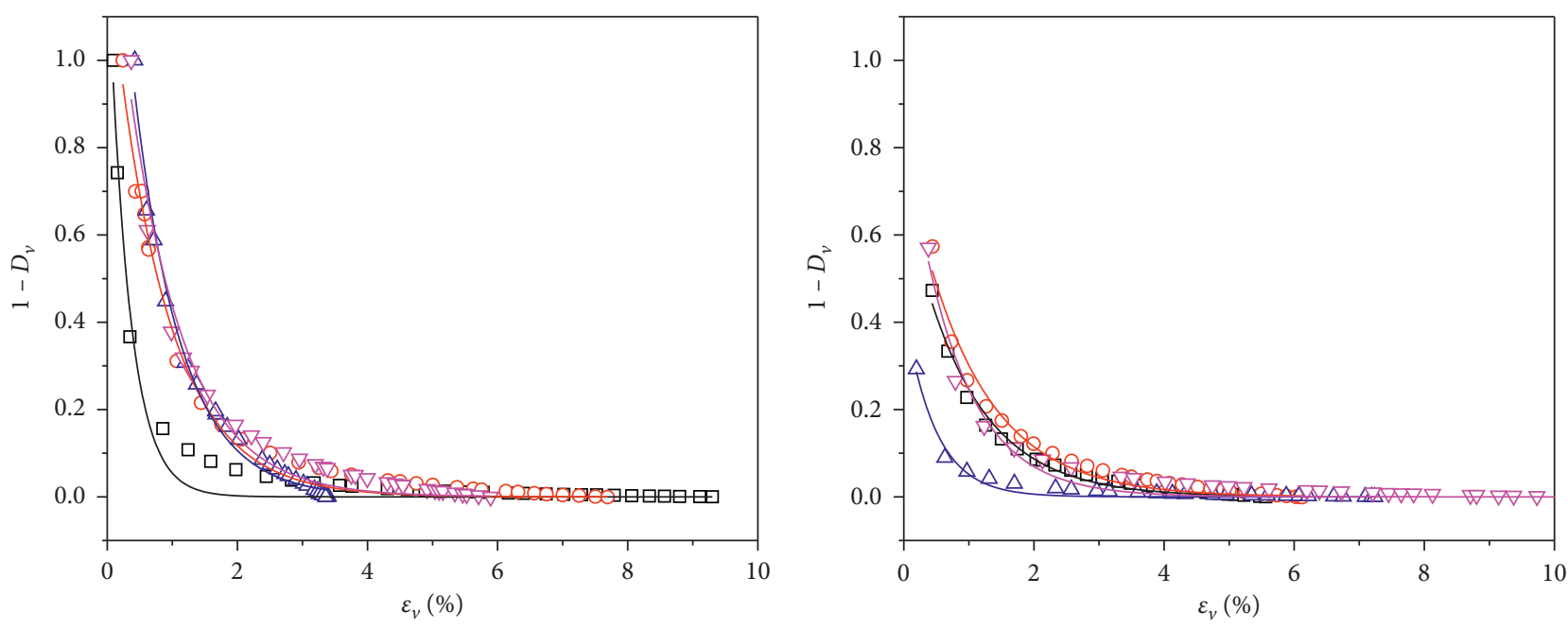

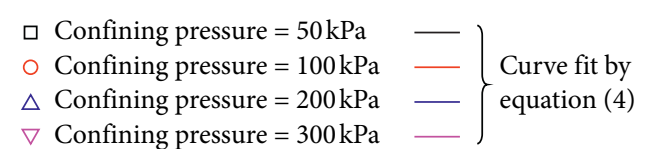

(a)

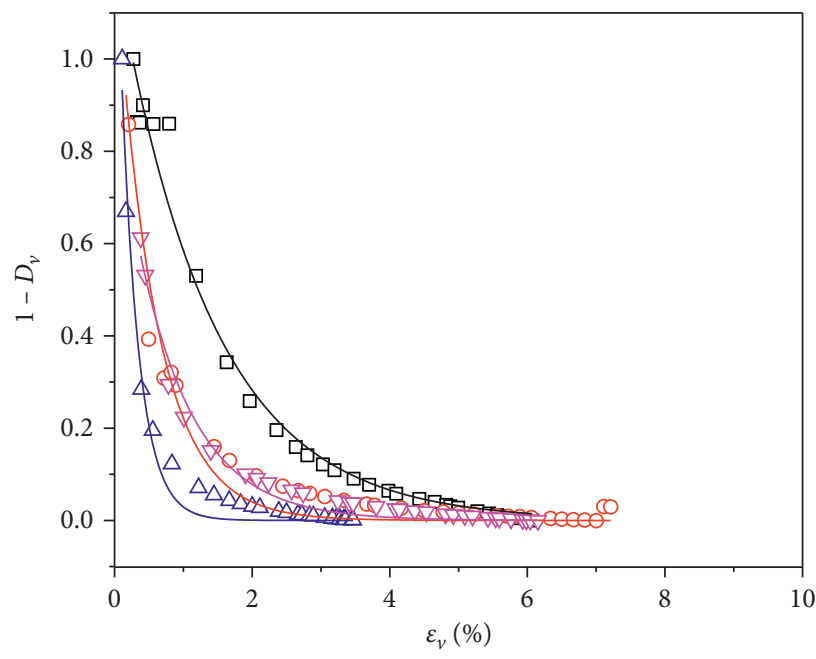

$\left.\begin{array}{ll}\square \text { Confining pressure }=50 \mathrm{kPa} & - \\ \bigcirc \text { Confining pressure }=100 \mathrm{kPa} & - \\ \triangle \text { Confining pressure }=200 \mathrm{kPa} & - \\ \nabla \text { Confining pressure }=300 \mathrm{kPa} & -\end{array}\right\} \begin{aligned} & \text { Curve fit by } \\ & \text { equation }(4)\end{aligned}$

(c)

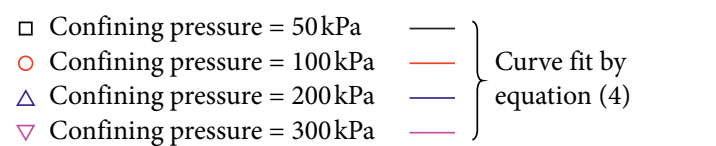

(b)

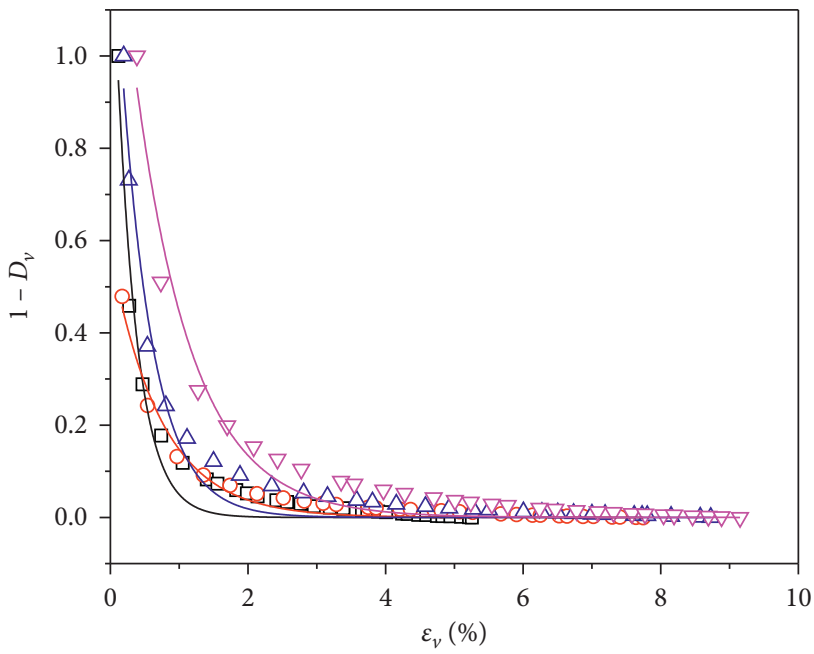

$\left.\begin{array}{ll}\square \text { Confining pressure }=50 \mathrm{kPa} & - \\ \bigcirc \text { Confining pressure }=100 \mathrm{kPa} & - \\ \triangle \text { Confining pressure }=200 \mathrm{kPa} & - \\ \nabla \text { Confining pressure }=300 \mathrm{kPa} & -\end{array}\right\} \begin{aligned} & \text { Curve fit by } \\ & \text { equation (4) }\end{aligned}$

(d)

Figure 5: Evolution laws of the disturbing function based on volumetric modulus. (a) Natural loess sample prepared at $8 \%$ water content; (b) natural loess sample prepared at $16 \%$ water content; (c) remolding loess sample prepared at $8 \%$ water content; (d) remolding loess sample prepared at $16 \%$ water content.

used to describe the natural structural loess. In the meantime, the elastic, plastic, or elasto-plastic models may be adopted to simulate the RI state of structural loess. In this study, the elastic model is selected to represent the RI state.

According to the generalized Hooke's law, the mean effective stress $p^{\prime}$ and deviatoric stress $q$ are calculated by

$$
\begin{gathered}
p^{\prime}=K \varepsilon_{v}^{i}, \\
q=3 G \varepsilon_{\mathcal{s}}^{i},
\end{gathered}
$$

where $K=$ bulk modulus, $G=$ shear modulus, $\varepsilon_{v}^{i}=$ volumetric strain at the RI state, and $\varepsilon_{s}^{i}=$ shear strain at the RI state. $K$ 

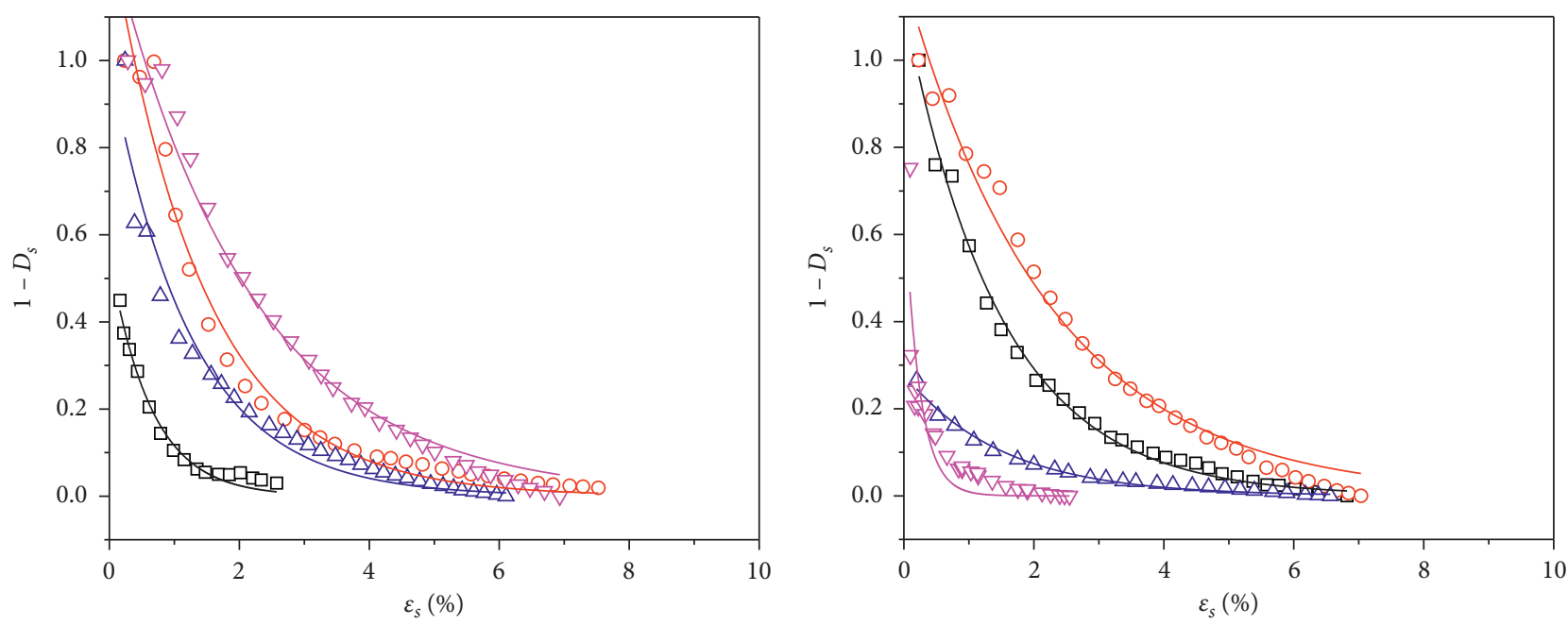

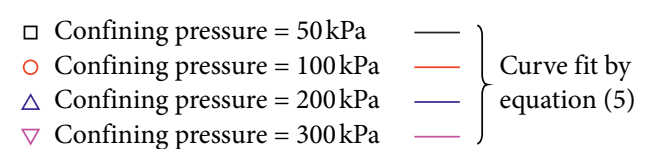

(a)

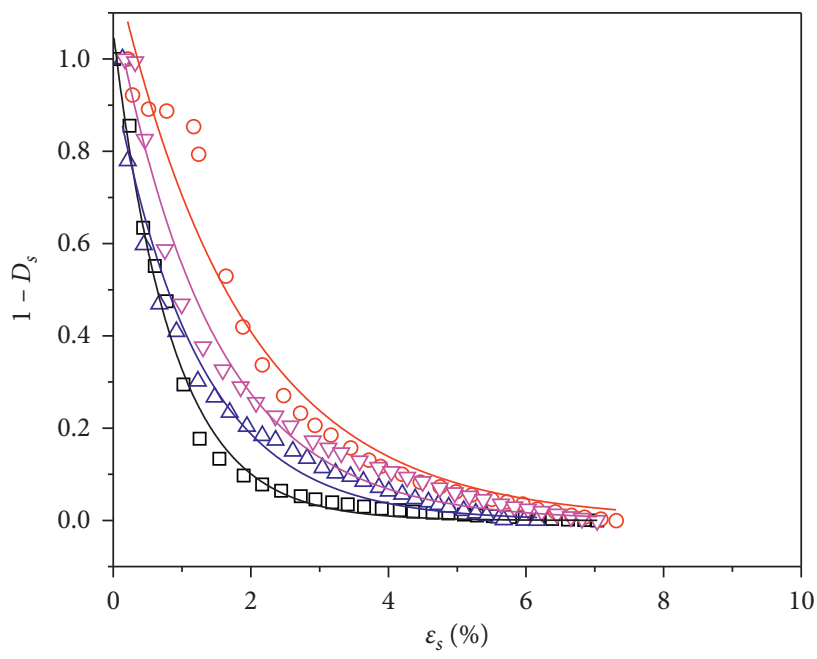

$\left.\begin{array}{ll}\square \text { Confining pressure }=50 \mathrm{kPa} & - \\ \bigcirc \text { Confining pressure }=100 \mathrm{kPa} & - \\ \Delta \text { Confining pressure }=200 \mathrm{kPa} & - \\ \nabla \text { Confining pressure }=300 \mathrm{kPa} & -\end{array}\right\} \begin{aligned} & \text { Curve fit by } \\ & \text { equation }(5)\end{aligned}$

(c)

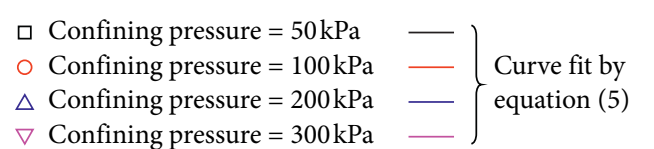

(b)

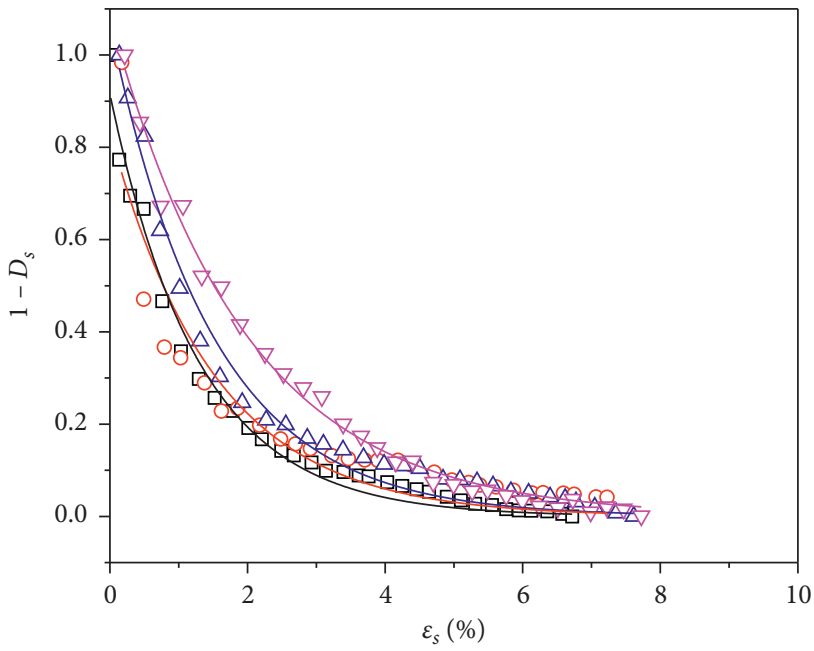

$\left.\begin{array}{ll}\square \text { Confining pressure }=50 \mathrm{kPa} & - \\ 0 \text { Confining pressure }=100 \mathrm{kPa} & - \\ \Delta \text { Confining pressure }=200 \mathrm{kPa} & - \\ \nabla \text { Confining pressure }=300 \mathrm{kPa} & -\end{array}\right\} \begin{aligned} & \text { Curve fit by } \\ & \text { equation }(5)\end{aligned}$

(d)

Figure 6: Evolution laws of the disturbing function based on shear modulus. (a) Natural loess sample prepared at $8 \%$ water content; (b) natural loess sample prepared at $16 \%$ water content; (c) remolding loess sample prepared at $8 \%$ water content; (d) remolding loess sample prepared at $16 \%$ water content.

and $G$ relate to Young's modulus $E$ and Poisson's ratio $v$ through

$$
\begin{aligned}
& K=\frac{E}{3(1-2 \nu)}, \\
& G=\frac{E}{2(1+\nu)} .
\end{aligned}
$$

The incremental form of equations (6a) and (6b) can be written as

$$
\left[\begin{array}{l}
d \varepsilon_{v}^{i} \\
d \varepsilon_{s}^{i}
\end{array}\right]=\left[\begin{array}{cc}
\frac{1}{K} & 1 \\
1 & \frac{1}{3 G}
\end{array}\right]\left[\begin{array}{l}
d p^{\prime} \\
d q
\end{array}\right]
$$




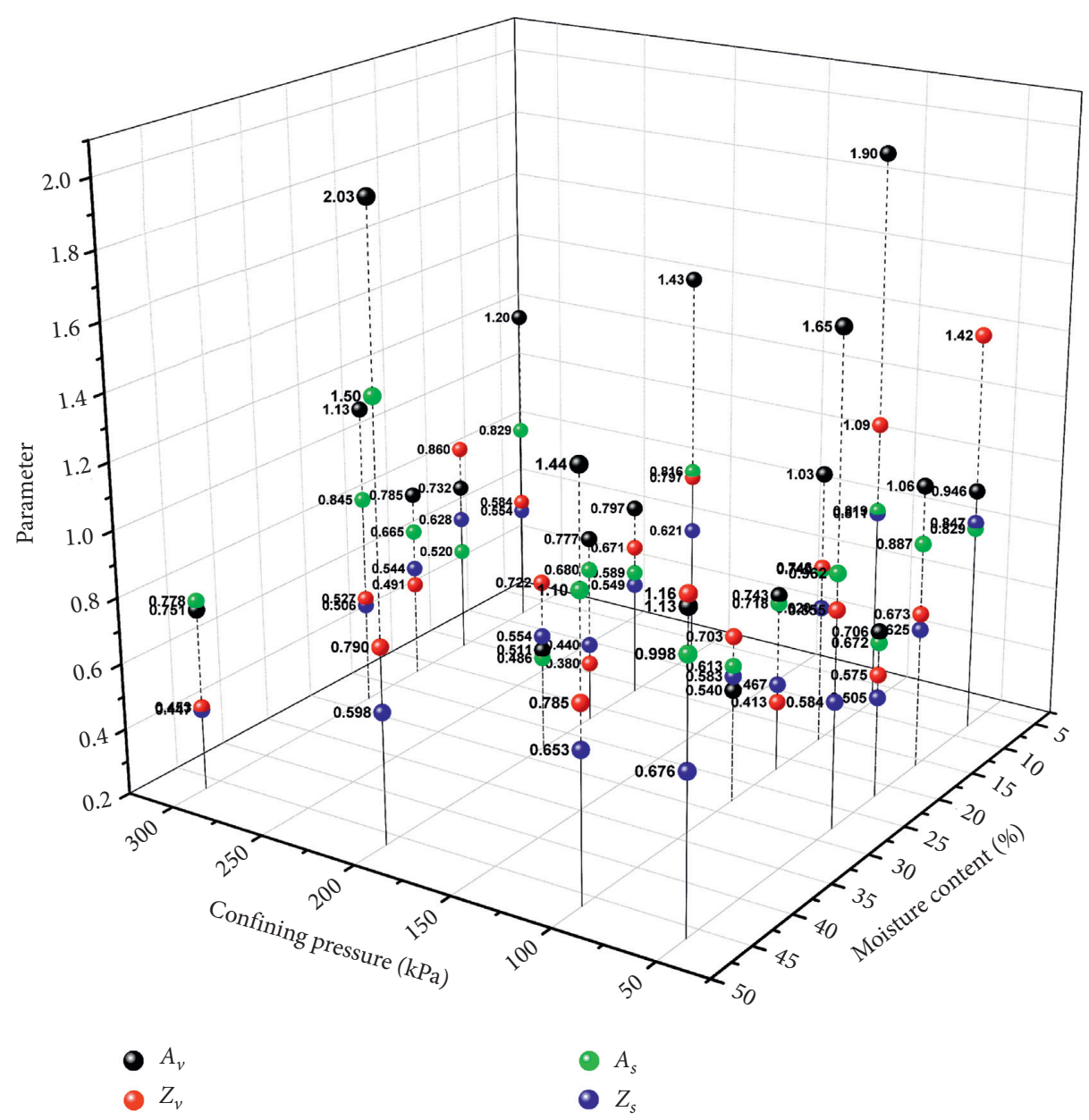

Figure 7: Parameters of the disturbing functions for natural loess specimens.

The parameters $K$ and $G$ in equation (8) can be computed, according to Liu and Carter [38], by

$$
\begin{aligned}
& K=\frac{v^{i} p^{i}}{k^{i}}, \\
& G=\frac{3(1-2 v) v^{i} p^{\prime}}{2(1+v) k^{i}}, \\
& v^{i}=1+e_{0}-k^{i} \ln p^{\prime},
\end{aligned}
$$

where $v_{i}=$ specific volume at the RI state, $e_{i}=$ void ratio at the RI state, $e_{0}=$ initial void ratio, and $k_{i}=$ initial elastic phase slope on $e_{i}-\ln p^{\prime}$ curve at the RI state.

For conventional triaxial compression tests at consolidated and drained conditions, we have

$$
d q=3 d p^{\prime} .
$$

Therefore, considering equation (10), the following relation is satisfied:

$$
\frac{d \varepsilon_{v}}{d \varepsilon_{s}}=\frac{G}{K} .
$$

The parameters $K$ and $G$ can be obtained with the help of the $\varepsilon_{v}$ versus $p^{\prime}$ curves and the $\varepsilon_{s}$ versus $\varepsilon_{v}$ curves. By substitution of the obtained $K$ and $G$ in equations (7a) and (7b), Young's modulus $E$ and Poisson's ratio $v$ is derived.

4.2. Model Formulation at the FA State. At the fully adjusted state, the volumetric strain increment $d \varepsilon_{v}^{c}$ and the shear strain increment $d \varepsilon_{s}^{c}$ can be obtained within the framework of the modified Cam-Clay (MCC) model. According to Bazant and Gilles [39], $d \varepsilon_{v}^{c}$ and $d \varepsilon_{s}^{c}$ has the form

$$
\begin{aligned}
& d \varepsilon_{v}^{c}=\kappa \frac{d p^{\prime}}{v^{c} p^{\prime}}+(\lambda-\kappa) \frac{d p_{0}^{\prime}}{v^{c} p_{0}^{\prime \prime}} \\
& d \varepsilon_{s}^{c}=\frac{2(1+v) \kappa}{9(1-2 v) v^{c}} \frac{d q}{p^{\prime}}+\frac{2 \eta}{M^{2}-\eta^{2}}(\lambda-\kappa) \frac{d p_{0}^{\prime}}{v^{c} p_{0}^{\prime}},
\end{aligned}
$$




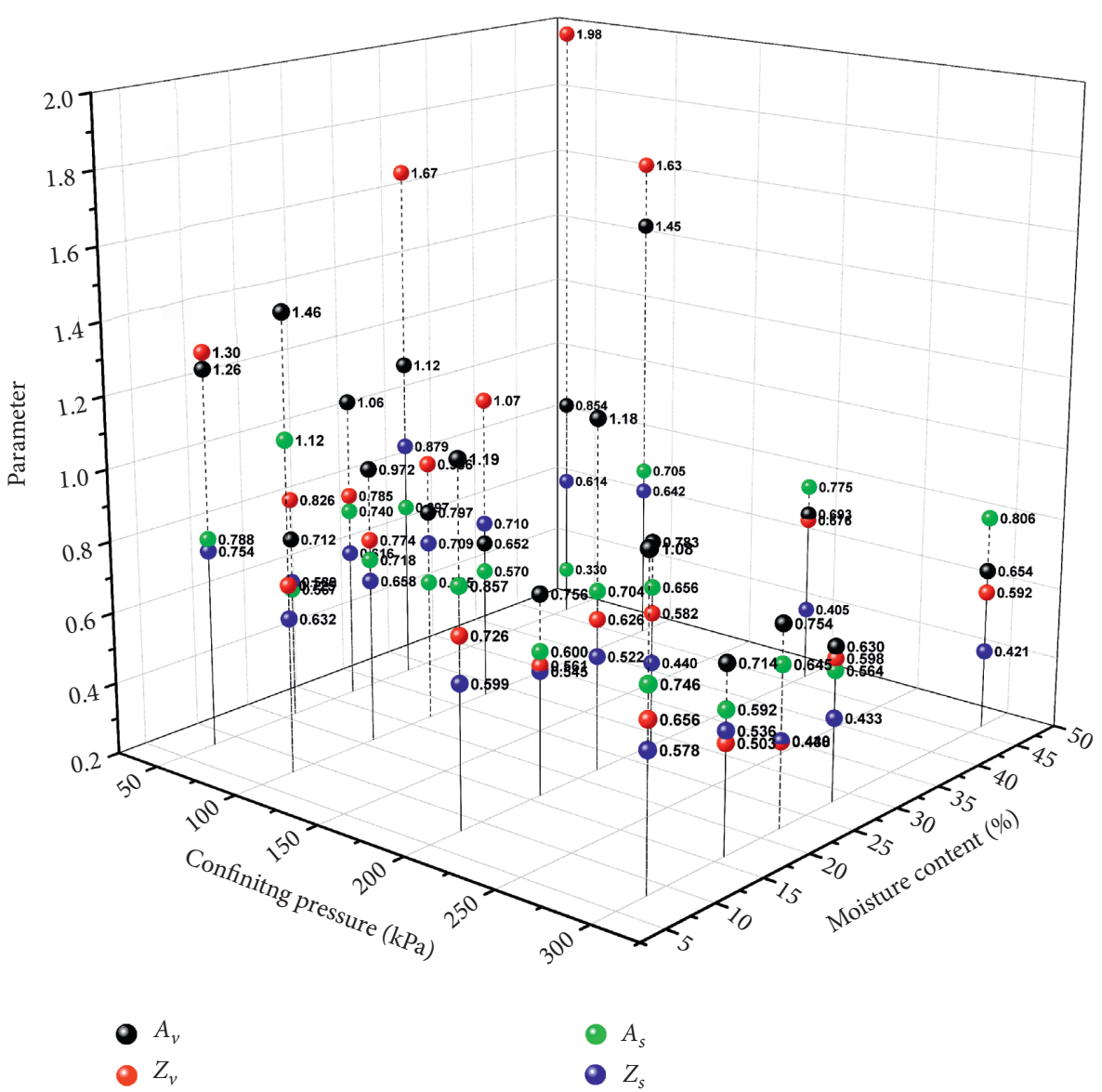

Figure 8: Parameters of the disturbing functions for remolding loess specimens.

where $v^{c}=1+e_{0}-(\lambda-\kappa) \ln p_{0}^{\prime}-\kappa \ln p^{\prime}$, the superscript $c$ denotes the FA state, and $\lambda$ and $\kappa$ are, respectively, the slopes of the normal consolidation and swelling lines. In general, $\lambda$ and $\kappa$ can be obtained from an isotropically loaded triaxial test or from an oedometer test.

The incremental relation between stress and strain for the soil at the FA state can be expressed as

$$
\begin{aligned}
{\left[\begin{array}{l}
d \varepsilon_{v}^{c} \\
d \varepsilon_{s}^{c}
\end{array}\right] } & =K_{f}\left[\begin{array}{ll}
K_{\kappa} & 1 \\
1 & K_{g}
\end{array}\right]\left[\begin{array}{l}
d p^{\prime} \\
d q
\end{array}\right], \\
K_{f} & =\frac{\lambda-\kappa}{v^{c}} \frac{2 \eta}{\left(M^{2}+\eta^{2}\right) p^{\prime}}, \\
K_{\kappa} & =\frac{\lambda M^{2}+(2 \kappa-\lambda) \eta^{2}}{2(\lambda-\kappa) \eta}, \\
K_{g} & =\frac{2(1+v) \kappa}{9(1-2 v)}\left(\frac{M^{2}+\eta^{2}}{2(\lambda-\kappa) \eta}\right)+\frac{2 \eta}{M^{2}-\eta^{2}},
\end{aligned}
$$

where $\eta=q / p^{\prime}$ and $M=$ frictional constant. For triaxial compression tests, $M$ is related to the effective stress friction angle, $\phi \prime$, through

$$
M=\frac{6 \sin \phi^{\prime}}{3-\sin \phi^{\prime}} .
$$

4.3. Model Incremental Form and Parameters. Based on the disturbed state concept as well as the evolution laws of the double-parameter disturbing function discussed above, the volumetric strain increment can be expressed as

$$
d \varepsilon_{v}=\left(1-D_{v}\right) d \varepsilon_{v}^{i}+D_{v} d \varepsilon_{v}^{c}+\left(\varepsilon_{v}^{c}-\varepsilon_{v}^{i}\right) d D_{v} .
$$

The shear strain increment is calculated as

$$
d \varepsilon_{s}=\left(1-D_{s}\right) d \varepsilon_{s}^{i}+D_{s} d \varepsilon_{s}^{c}+\left(\varepsilon_{s}^{c}-\varepsilon_{s}^{i}\right) d D_{s} .
$$

Therefore, the constitutive model for the structural loess based on the disturbed state concept has the form 


$$
\begin{aligned}
{\left[\begin{array}{l}
d \varepsilon_{v} \\
d \varepsilon_{s}
\end{array}\right]=} & {\left[\begin{array}{cc}
\frac{1-D_{v}}{K}+D_{v} K_{f} K_{k} & D_{v} K_{f} \\
D_{s} K_{f} & \frac{1-3 D_{s}}{3 G}+D_{s} K_{f} K_{g}
\end{array}\right]\left[\begin{array}{l}
d p^{\prime} \\
d q
\end{array}\right] } \\
& +\left[\begin{array}{cc}
\varepsilon_{v}^{c}-\varepsilon_{v}^{i} & 0 \\
0 & \varepsilon_{s}^{c}-\varepsilon_{s}^{i}
\end{array}\right]\left[\begin{array}{l}
d D_{v} \\
d D_{s}
\end{array}\right] .
\end{aligned}
$$

By substituting equations (4) and (5) into equation (17), one can obtain

$$
\begin{aligned}
{\left[\begin{array}{l}
d p^{\prime} \\
d q
\end{array}\right] } & =A\left[\begin{array}{ll}
K_{v v} & K_{v s} \\
K_{s v} & K_{s s}
\end{array}\right]\left[\begin{array}{l}
d \varepsilon_{v} \\
d \varepsilon_{s}
\end{array}\right], \\
A & =\frac{1}{\left(\left(\left(1-D_{v}\right) / K\right)+D_{v} K_{f} K_{k}\right)\left(\left(\left(1-D_{s}\right) / 3 G\right)+D_{s} K_{f} K_{g}\right)-D_{v} D_{s} K_{f}^{2}} \\
K_{v v} & =\left(\frac{1-D_{s}}{3 G}+D_{s} K_{f} K_{g}\right)\left(1-\left(\varepsilon_{v}^{c}-\varepsilon_{v}^{i}\right)\left(A_{v} Z_{v} \exp \left(-Z_{v} \varepsilon_{v}\right)\right)\right)-D_{v} K_{f} \\
K_{v s} & =\left(\frac{1-D_{s}}{3 G}+D_{s} K_{f} K_{g}\right)-D_{v} K_{f}\left(1-\left(\varepsilon_{s}^{c}-\varepsilon_{s}^{i}\right)\left(A_{s} Z_{s} \exp \left(-Z_{s} \varepsilon_{s}\right)\right)\right) \\
K_{s v} & =\left(\frac{1-D_{v}}{K}+D_{v} K_{f} K_{k}\right)-D_{s} K_{f}\left(1-\left(\varepsilon_{v}^{c}-\varepsilon_{v}^{i}\right)\left(A_{v} Z_{v} \exp \left(-Z_{v} \varepsilon_{v}\right)\right)\right) \\
K_{s s} & =\left(\frac{1-D_{v}}{K}+D_{v} K_{f} K_{k}\right)\left(1-\left(\varepsilon_{s}^{c}-\varepsilon_{s}^{i}\right)\left(A_{s} Z_{s} \exp \left(-Z_{s} \varepsilon_{s}\right)\right)\right)-D_{s} K_{f} .
\end{aligned}
$$

For conventional triaxial compression tests, where $d q=3 d p^{\prime}$, a manipulation of equation (18) leads to the derivation of the final incremental form of the proposed constitutive model which is expressed as

$$
\begin{gathered}
d p^{\prime}=A\left(K_{v v}+K_{v s} \frac{K_{s v}-3 K_{v v}}{3 K_{v s}-K_{s s}}\right) d \varepsilon_{v}, \\
d q=A\left(K_{s v}+K_{s s} \frac{K_{s v}-3 K_{v v}}{3 K_{v s}-K_{s s}}\right) d \varepsilon_{v} .
\end{gathered}
$$

From equations (24a) and (24b), it can be indicated that the parameters of the proposed constitutive model are $\nu, E, \lambda$, $\kappa, M, A_{v}, Z_{v}, A_{s}$, and $Z_{s}$. These parameters in the model can be obtained through the conventional laboratory tests, which lay the foundation for popularizing and applying this model in engineering practice. The proposed constitutive model has the ability to account for the structural effect of loess, which provides a mathematical means for investigating the structural behavior of loess soil under various conditions. This is because that the incorporated disturbing function in the proposed constitutive model is capable of simulating the effect of water content and confining pressure on loess structural behavior and describing the variations of bulk modulus and shear modulus with stress.
4.4. Model Verification. To verify the constructed constitutive model for structural loess, scaled model tests with the ratio of similitude being $1 / 100$ were carried out on a rafted pile group foundation in Xi'an loess soil. The model tests were conducted by the research group in the geotechnicalmechanics laboratory of Xi'an University of Architecture and Technology. The prototype of the model test is a highrise building with 36 floors above the ground and 2 floors below the ground. The embedded depth of the foundation is about $6 \mathrm{~m}$. The adopted foundation form is the piled raft foundation, and the structural form is the reinforced concrete tube-in-tube structure. The load ratio of the central core tube to its surrounding is about $3: 1$. The pile cap is a steel plate which is about $50 \mathrm{~cm}$ both in length and width and is $1 \mathrm{~cm}$ in thickness. In terms of the pile foundation, the cast in situ bored pile of $2 \mathrm{~m}$ in diameter and $50 \mathrm{~m}$ in length was adopted. The model tests were conducted within a steel box of $1.5 \mathrm{~m}$ in length and width and $1 \mathrm{~m}$ in height. The model pile was simulated with a hollow aluminium tube of $0.5 \mathrm{~m}$ in length, $20 \mathrm{~mm}$ in external diameter, $1 \mathrm{~mm}$ in wall thickness, and $0.495 \mathrm{~m}$ in penetration depth into the soil. A steel file was used to rough the surface of the model pile. A photograph of the model test setup and the monitoring point plan view is shown in Figure 9. 


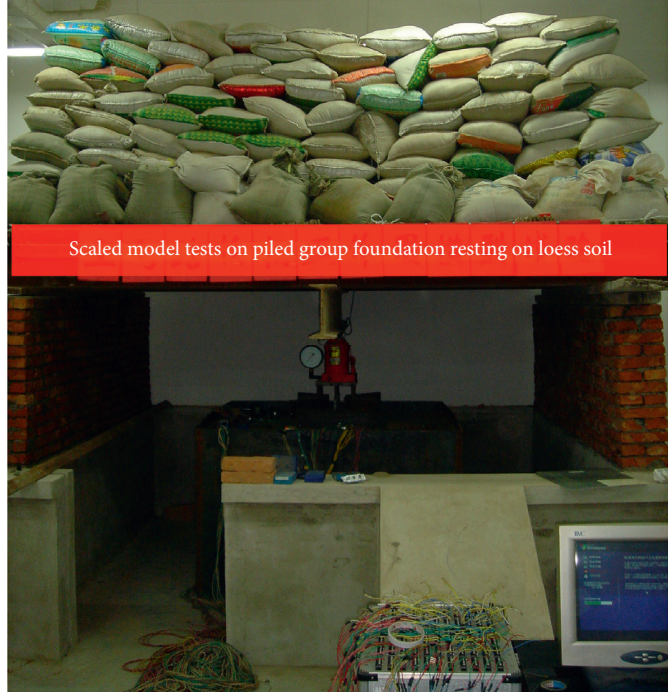

(a)

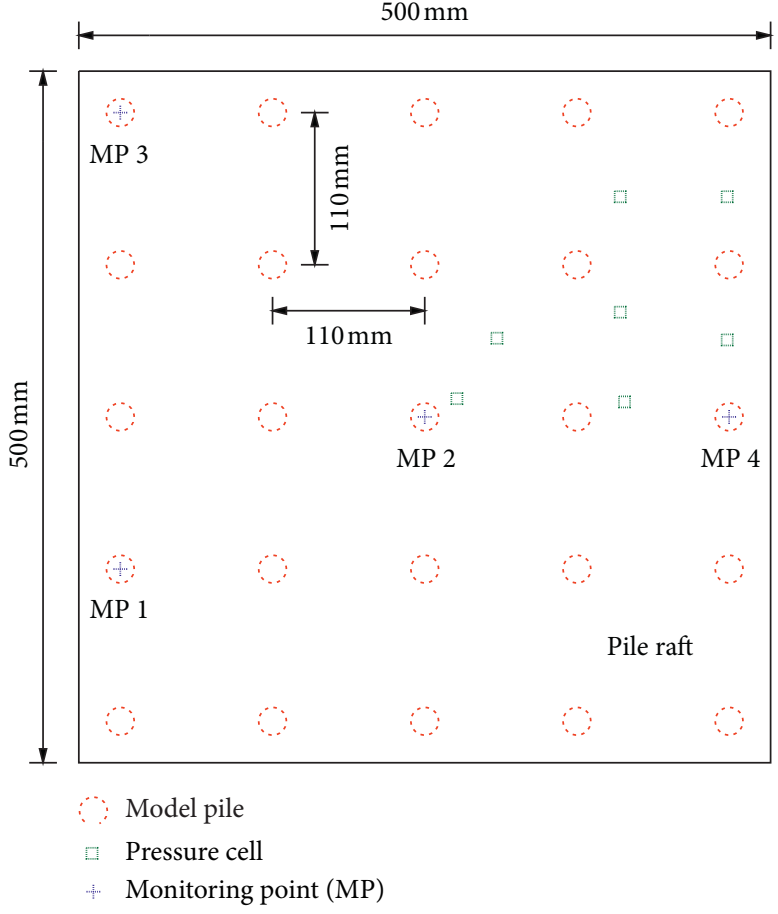

(b)

Figure 9: Photograph of the model test: (a) model test setup; (b) monitoring point plan view.

The research group has undertaken an analysis of the settlement of the foundation, the load bearing capacity for different piles in the group, the distribution and development of the subsidiary stress of the loess soil under the cap, the properties of the side friction and the pile top reaction of the piles with featured characteristics, and the effect of rising the underground water level on the working performance of the pile foundation. The specific situation of the model, the relevant parameters in the model, and the research achievements can be found in the reference literature [40].

In order to verify the rationality and the practicability of the proposed constitutive model for the structural loess soil, the proposed constitutive model was embedded into ABAQUS through the subroutine interface, and it has been specifically illustrated in the reference literature [31]. Symmetry was considered in the numerical analysis for reducing the computation amount. The overall dimension of the numerical analysis model was taken as $75 \mathrm{~m} \times 75 \mathrm{~m} \times 100 \mathrm{~m}$. The C3D8R elements were used for the model pile, while the linear C3D8RP elements were used for the soil. As for the boundary conditions, the left-hand side of the model was applied with symmetry constraint, the right-hand side was horizontal constraint, the bottom surface was fixed constraint, and the top surface was left free.

Finite element analysis using the proposed constitutive model and the modified Cam-Clay model were performed to simulate the loading process of the model tests. The input parameters required for numerical simulation is summarized in Table 2. A comparison of the finite element analysis results and the model test results is presented in Figure 10.
TABLE 2: Input parameters required for finite element analysis.

\begin{tabular}{lc}
\hline Parameter & Magnitude \\
\hline Poisson's ratio, $v$ & 0.28 \\
Young's modulus $(\mathrm{kPa}), E$ & 5108 \\
Slope of the normal consolidation line, $\lambda$ & 0.1819 \\
Slope of the swelling line, $\kappa$ & 0.012 \\
Frictional constant, $M$ & 1.396 \\
Parameter of the disturbing function based on & 0.7056 \\
volumetric modulus, $A_{v}$ & \\
Parameter of the disturbing function based on & 0.5748 \\
volumetric modulus, $Z_{v}$ & \\
Parameter of the disturbing function based on shear & 0.6724 \\
modulus, $A_{s}$ & \\
$\begin{array}{l}\text { Parameter of the disturbing function based on shear } \\
\text { modulus, } Z_{s}\end{array}$ & 0.5051 \\
\hline
\end{tabular}

It can be indicated from Figure 10 that the calculated results by ABAQUS using the proposed constitutive model are consistent with the measured results. It proves the rationality of the double-parameter disturbing function defined in this paper and proves the rationality and practicability of the proposed constitutive model for structural loess based on the disturbed state concept.

In addition, for the purpose of further validating the performance of the proposed constitutive model, a comparison of the stress-strain relations derived by testing and the proposed constitutive model at various confining pressures is made in Figure 11. It can be indicated that a good agreement exists between the results of testing and the results of the proposed constitutive model, demonstrating 


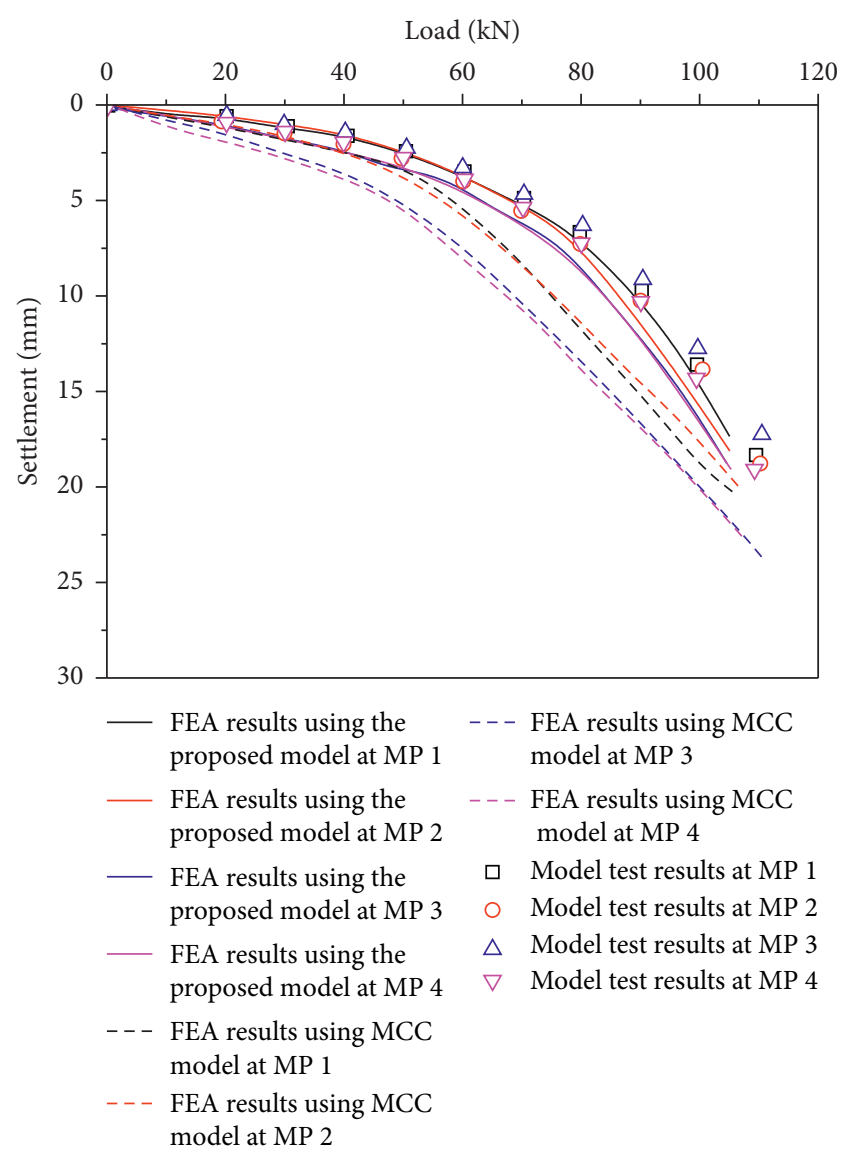

FIgURE 10: Comparison of the load versus settlement curves between the finite element analysis (FEA) results and the model test results.

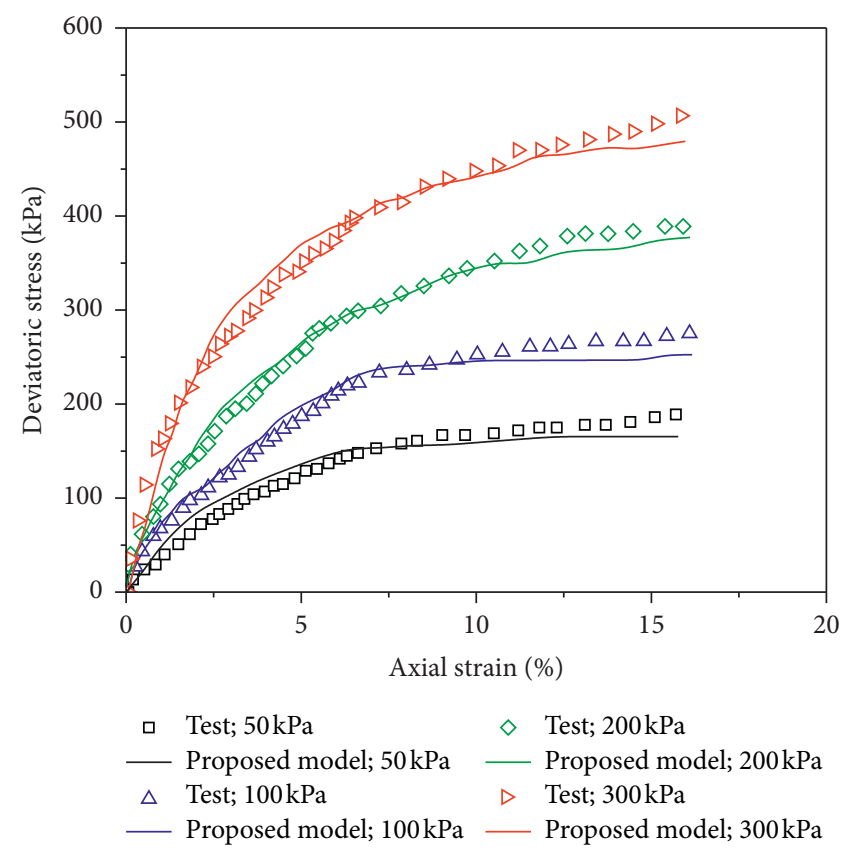

FIGURE 11: Comparison of the stress versus strain curves between the results of the proposed constitutive model results and the triaxial compression testing results. the satisfactory performance of the proposed constitutive model for structural loess soil.

\section{Conclusions}

Drained and consolidated triaxial compression experiments were carried out on natural and remolding loess specimens prepared at different water contents. A two-parameter disturbing function with the volumetric and shear moduli as its parameters was proposed and the disturbing function evolution laws were discussed on the basis of the disturbed state concept. By incorporating the disturbing function into the modified Cam-Clay model, a new constitutive model accounting for the structural behavior of loess was established. The model was then challenged against the model test results on a rafted pile group foundation. The main conclusions drawn in this study are summarized as follows:

(i) The effect of water content and confining pressure on the structure of loess is remarkable, and the influencing degree is different. At a confining pressure greater than $200 \mathrm{kPa}$, the effect of the variation of water content on the loess structure is tenuous. At a water content greater than $22 \%$, the effect of increasing water content on the loess structure is feeble.

(ii) The evolution characteristics of the disturbing functions based on shear and volumetric moduli can be well described in exponential forms. The parameters characterizing the exponential evolution laws vary, depending on confining pressure, water content, and sample type.

(iii) The established constitutive model based on the disturbed state concept can well capture the structural mechanical properties of the loess. The model parameters have clarified physical meanings and are convenient to be obtained by common laboratory tests.

(iv) A good agreement between the finite element analysis results using the established constitutive model and the model test results verifies the rationality and practicability of the established constitutive model for structural loess soil. Therefore, this model has the potential to be applied to predict the load-settlement behavior of pile group foundation in the loess region.

\section{Data Availability}

The data used to support the findings of this study are available from the corresponding author upon request.

\section{Disclosure}

The funders had no role in the design of the study, in the collection, analyses, or interpretation of data, in the writing of the manuscript, or in the decision to publish the results.

\section{Conflicts of Interest}

The authors declare no conflicts of interest. 


\section{Authors' Contributions}

P. G. and Y. W. conceptualized the study; Y. X. developed methodology; Y. X. developed software; P. G. validated the study; Y. X. carried out formal analysis; Y. X. investigated the study; K. C. helped with the resources; Y. X. carried out data curation; G. L. wrote the original draft; P. G. and C. Z. reviewed and edited the article; Y. X. visualized the study; P. G. supervised the study; Y. X. administered the project; Y. X. carried out funding acquisition. All authors have read and agreed to the published version of the manuscript.

\section{Acknowledgments}

This research was funded by the Natural Science Fund of the University in Anhui Province (Grant nos. KJ2019ZD60 and KJ2013B223), Excellent Young Talents Foundation Project in Anhui Province (Grant no. 2012SQRL195), Talent Introduction in Hefei University (Grant no. 13RC10), Provincial Quality Engineering Projects of the Education Department of Anhui Province (Grant no. 2017zhkt383), Undergraduate Education Quality Project in Hefei University (Grant nos. 2018HFMOOC04 and 2018HFJC05), and National Natural Science Foundation of China (Grant no. 42077249).

\section{References}

[1] J. Zhang, A. Soltani, A. Deng, and M. Jaksa, "Mechanical performance of jute fiber-reinforced micaceous clay composites treated with ground-granulated blast-furnace slag," Materials, vol. 12, no. 4, p. 576, 2019.

[2] C. Yin, W. Zhang, X. Jiang, and Z. Huang, "Effects of initial water content on microstructure and mechanical properties of lean clay soil stabilized by compound calcium-based stabilizer," Materials, vol. 11, no. 10, p. 1933, 2018.

[3] P. K. K. Wong and P. K. K. Wong, "Yielding and plastic flow of sensitive cemented clay," Géotechnique, vol. 25, no. 4, pp. 763-782, 1975.

[4] M. D. Liu and J. P. Carter, "A structured Cam clay model," Canadian Geotechnical Journal, vol. 39, no. 6, pp. 1313-1332, 2002.

[5] C. S. Desai, "A consistent finite element technique for work softening behavior," in Proceedings of International Conference on Computer Methods and Nonlinear Mechanics, pp. 403-419, Austin, TX, USA, March 1974.

[6] C. S. Desai, S. Somasundaram, and G. Frantziskonis, "A hierarchical approach for constitutive modelling of geologic materials," International Journal for Numerical and Analytical Methods in Geomechanics, vol. 10, no. 3, pp. 225-257, 1986.

[7] C. S. Desai and J. Toth, "Disturbed state constitutive modeling based on stress-strain and nondestructive behavior," International Journal of Solids and Structures, vol. 33, no. 11, pp. 1619-1650, 1996.

[8] C. S. Desai, "Constitutive modeling of materials and contacts using the disturbed state concept: part 1-background and analysis," Computers \& Structures, vol. 146, no. 1, pp. 214-233, 2015.

[9] C. S. Desai, "Disturbed state concept as unified constitutive modeling approach," Journal of Rock Mechanics and Geotechnical Engineering, vol. 8, no. 3, pp. 277-293, 2016.
[10] Z. J. Shen, "Pile masonry model of structural clay," Geotechnical Mechanics, vol. 21, pp. 1-4, 2000.

[11] Z. J. Shen, "Elastoplastic damage of model of structural clay," Journal of Geotechnical Engineering, vol. 15, pp. 21-28, 1993.

[12] Z. J Shen and Z. Q. Hu, "Binary medium model of loess," Journal of Hydraulic Engineering, vol. 7, pp. 1-6, 2003.

[13] Y. Xiao, Y. Sun, F. Yin, H. Liu, and J. Xiang, "Constitutive modeling for transparent granular soils," International Journal of Geomechanics, vol. 17, no. 7, 22 pages, Article ID 04016150, 2017.

[14] Y. Xiao and C. S. Desai, "Constitutive modeling for overconsolidated clays based on disturbed state concept. II: validation," International Journal of Geomechanics, vol. 19, no. 9, p. 11, Article ID 04019102, 2019.

[15] Y. Xiao and C. S. Desai, "Constitutive modeling for overconsolidated clays based on disturbed state concept. I: theory," International Journal of Geomechanics, vol. 19, no. 9, p. 18, Article ID 04019101, 2019.

[16] Y. Xiao and H. Liu, "Elastoplastic constitutive model for rockfill materials considering particle breakage," International Journal of Geomechanics, vol. 17, no. 1, p. 13, Article ID 04016041, 2017.

[17] Z. H. Chen, "Discussion on effective stress of unsaturated soil," Journal of Geotechnical Engineering, vol. 16, pp. 62-69, 1994.

[18] X. Fang, C. Shen, Z. Cheng, and W. Zhang, "Triaxial wetting tests of intact Q2 loess by computed tomography," China Civil Engineering Journal, vol. 44, no. 11, pp. 98-106, 2011.

[19] X. W. Fang, C. N. Shen, and L. Wang, "Research on microstructure of Q2 loess before and after wetting," Rock and Soil Mechanics, vol. 34, pp. 1319-1324, 2013.

[20] M. Jiang, H. Hu, and F. Liu, "Summary of collapsible behaviour of artificially structured loess in oedometer and triaxial wetting tests," Canadian Geotechnical Journal, vol. 49, no. 10, pp. 1147-1157, 2012.

[21] M. Jiang, F. Zhang, H. Hu, Y. Cui, and J. Peng, "Structural characterization of natural loess and remolded loess under triaxial tests," Engineering Geology, vol. 181, no. 10, pp. 249-260, 2014.

[22] T. D. Miao, S. Y. Liu, and J. S. Ren, "Deformation mechanism and constitutive relation of collapsible loess," Chinese Journal of Geotechnical Engineering, vol. 21, pp. 383-387, 1999.

[23] L. X. Gao, M. T. Luan, and S. Q. Li, "Analysis of microstructure parameters of collapsible loess based on SEM images," Journal of Convergence Information Technology, vol. 6, no. 5, pp. 32-43, 2011.

[24] E. Romero and P. H. Simms, "Microstructure investigation in unsaturated soils: a review with special attention to contribution of mercury intrusion porosimetry and environmental scanning electron microscopy," in Laboratory and Field Testing of Unsaturated Soils, pp. 93-115, Springer, Dordrecht, Netherlands, 2008.

[25] S. Y. Lei and W. D. Tang, "Analysis of microstructure change for loess in the process of loading and collapse with CT scanning," Chinese Journal of Rock Mechanics and Engineering, vol. 23, pp. 4166-4169, 2004.

[26] J. G. Li, Z. H. Cheng, and X. F. Huang, "CT-triaxial test for collapsibility of natural Q3 loess," Chinese Journal of Rock Mechanics and Engineering, vol. 29, no. 6, pp. 1288-1296, 2010.

[27] Y. Luo, D. Xie, S. Shao, and A. Zhang, "Structural parameter of soil under complex stress conditions," Chinese Journal of Rock Mechanics and Engineering, vol. 23, pp. 4248-4251, 2004. 
[28] C. L. Chen, Z. Q. Hu, and P. Gao, "Research on relationship between structure and deformation property of intact loess," Rock and Soil Mechanics, vol. 27, pp. 1891-1896, 2006.

[29] C. L. Chen, X. Jiang, T. Z. Su, J. Jin, and W. W. Li, "The effect of structure on unconfined compression characteristics of compacted loess," Chinese Journal of Rock Mechanics and Engineering, vol. 33, pp. 2539-2545, 2014.

[30] F. Wang, G. Y. Li, Y. H. Mu, Y. H. Wu, and S. Z. Fan, "Study on collapse characteristic of compacted loess subjected to cyclic drying and wetting," Journal of Glaciology and Geocryology, vol. 38, pp. 416-423, 2016.

[31] Y. Xu, "Research on the disturbed state constitutive model of the structural loess and application," Ph.D. thesis, Xi'an University of Architecture and Technology, Xi'an, China, 2011.

[32] Y. Xu, "Experimental study on one-dimensional disturbance evolution of Q3 loess," Journal of West Anhui University, vol. 34, pp. 110-114, 2018.

[33] Y. Xu, "A 1D compression model for loess based on disturbed state concept," Revue des Composites et des Materiaux Avances, vol. 29, pp. 125-129, 2019.

[34] Y. Xu and P. Guo, "Disturbance evolution behavior of loess soil under triaxial compression," Advances in Civil Engineering, vol. 2020, Article ID 4160898, 14 pages, 2020.

[35] P. Guo, X. Gong, and Y. Wang, "Displacement and force analyses of braced structure of deep excavation considering unsymmetrical surcharge effect," Computers and Geotechnics, vol. 113, p. 17, Article ID 103102, 2019.

[36] C. Yang, X. Liu, X. Liu, C. Yang, and J. P. Carter, "Constitutive modelling of Otaniemi soft clay in both natural and reconstituted states," Computers and Geotechnics, vol. 70, pp. 8395, 2015 .

[37] Ministry of Transport of the People's Republic of China, JTG 3430-2020: Test Methods of Soils for Highway Engineering, China Communications Press, Beijing, China, 2020.

[38] M. D Liu and J. P. Carter, "A structured cam clay model," Center for Geotechnical Research, vol. 39, pp. 1313-1332, 2002.

[39] Z. P. Bazant and P. C. Gilles, "Nonlocal continuum damage, localization instability and convergence," Journal of Applied Mechanics, vol. 121, pp. 287-293, 1988.

[40] Y. Xu, "The model test of super-long large-diameter pile foundation in loess area and non-linear finite element analysis," M.S. thesis, Xi'an University of Architecture and Technology, Xi'an, China, 2009. 